Alma Mater Studiorum - Università di Bologna DEPARTMENT OF ECONOMICS

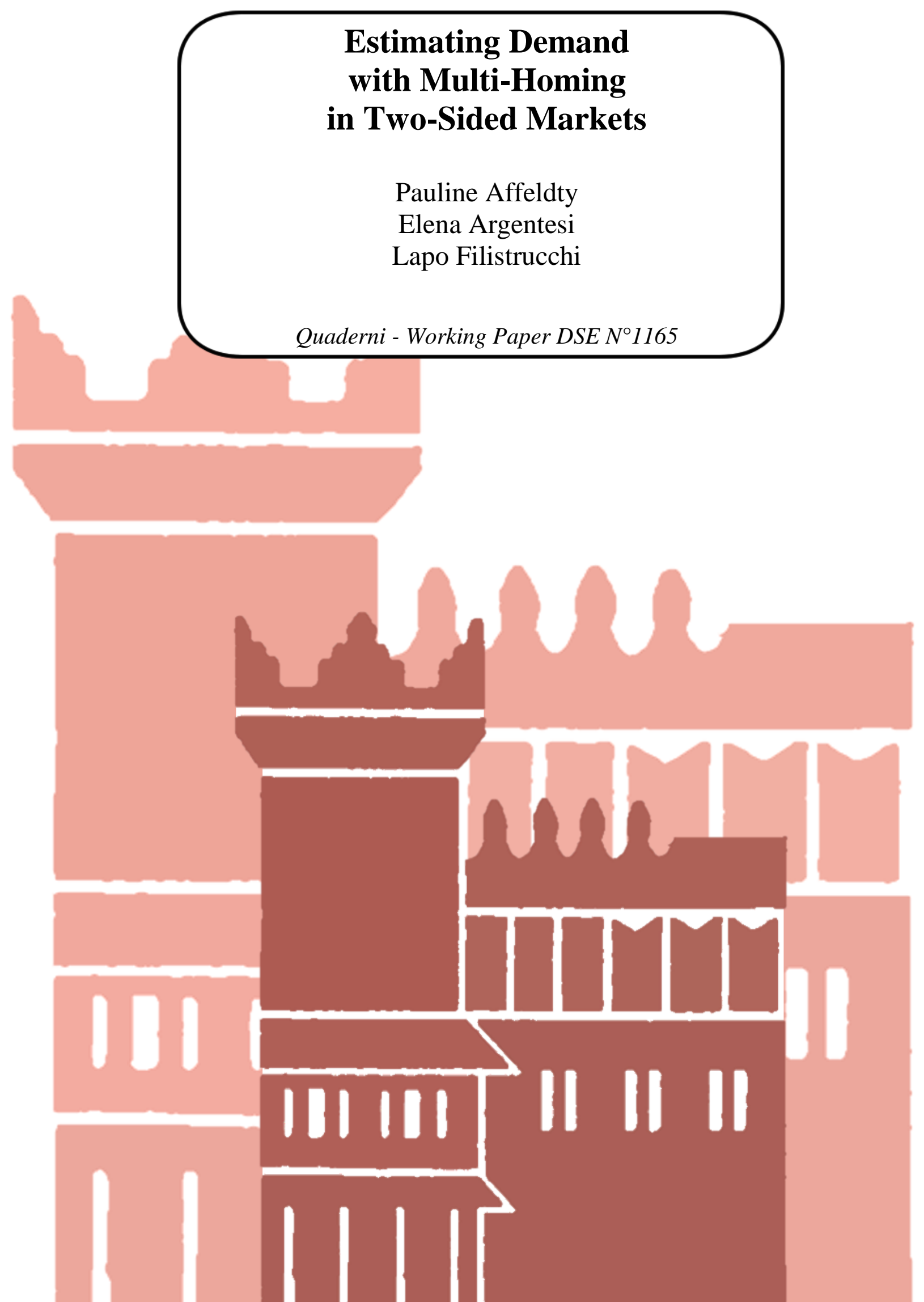




\title{
Estimating Demand with Multi-Homing in Two-Sided Markets*
}

\author{
Pauline Affeldt ${ }^{\dagger}$ Elena Argentesi ${ }^{\dagger}$ and Lapo Filistrucchi ${ }^{\S}$
}

August 18, 2021

\begin{abstract}
We empirically investigate the relevance of multi-homing in two-sided markets. First, we build a micro-founded structural econometric model that encompasses demand for differentiated products and allows for multi-homing on both sides of the market. We then use an original dataset on the Italian daily newspaper market that includes information on double-homing by readers to estimate readers' and advertisers' demand. The results show that an econometric model that does not allow for multihoming is likely to produce biased estimates of demand on both sides of the market. In particular, on the reader side, accounting for multi-homing helps to recognize complementarity between products; on the advertising side, it allows to measure to what extent advertising demand depends on the shares of exclusive and overlapping readers.
\end{abstract}

JEL Classification: C51, D43, L13, L82, M37

Keywords: two-sided markets, platforms, multi-homing, media, advertising

\footnotetext{
*We thank Emilio Calvano, Tomaso Duso, Lukasz Grzybowski, Alessandro Iaria, Marc Ivaldi, Radosveta Ivanova-Stenzel, Bruno Jullien, Tobias Klein, Leonardo Madio, Andrea Mantovani, Valerio Serse, Senay Sokullu, Hannes Ullrich, Axel Werwatz, Christine Zulehner, as well as participants at the 2018 Media Economics Workshop, the 4th Economics of Media Bias Workshop, the 2019 Annual Scientific Seminar on Media and the Digital Economy, the 2019 MaCCI Annual Conference, the 11th Paris Conference on Digital Economics, the 3rd Doctoral Workshop on The Economics of Digitization, the 4th Economics of Platforms Workshop, the 46th Annual Conference of the European Association for Research in Industrial Economics, and the IO seminar series in Toulouse for helpful comments.

${ }^{\dagger}$ Deutsches Institut für Wirtschaftsforschung (DIW Berlin) \& Technische Universität (TU) Berlin. E-mail: paffeldt@ diw.de.

$\ddagger$ Department of Economics, University of Bologna. E-Mail: elena.argentesi@ unibo.it.

${ }^{\S}$ Department of Economics and Management, University of Florence and CentER \& TILEC, Tilburg University. E-Mail: lapo.filistrucchi@unifi.it.
} 


\section{Non-Technical Summary}

Two-sided markets are markets in which firms sell two products or services to two different types of consumers, taking into account that the two demands are linked by indirect network effects. Examples of such markets are media markets, where demand for advertising is related to the size of the audience, and the market for online social networks, where advertising demand depends on the number of users.

With the emergence of digital technologies, multi-homing, i.e. users patronizing multiple outlets, has become a widespread phenomenon in media markets. For instance, newspaper readers can now access multiple online news outlets with just a few clicks, no longer needing to buy and carry a pile of different newspapers, then physically leafing through them. Similarly, TV viewers now have access to many more digital channels. Thus, effectively consumers more frequently multi-home.

We empirically study the role of multi-homing in two-sided markets. First, we build an econometric model that encompasses demand on both sides of the market and allows for multi-homing on each side. We then estimate the model using data on Italian daily newspapers, alternatively taking into account and not taking into account information on multi-homing by readers.

Readers' demand is estimated using a nested logit model, where the structure of the nests draws on the traditional classification of national daily newspapers between generalist, sport, and financial. We incorporate information on multi-homing by readers by allowing them to choose between bundles of newspapers. We show that not accounting for multi-homing leads to a substantial bias in the estimation of own- and cross-price elasticities on the readers' side of the market. In particular, own-price elasticities are larger when readers' multi-homing is taken into account. Allowing for multi-homing recognizes that, when the price of one newspaper rises, those readers that actually multi-home on that newspaper may have more and closer substitute bundles to switch to with respect to when they are assumed to singlehome. Thus, readers may turn out to be more price-sensitive when their multi-homing is taken into account. Furthermore, while newspapers are assumed to be substitutes in the single-homing model, they can be substitutes or complements when multi-homing by readers is taken into account. Indeed, we find that while newspapers of the same type are substitutes, newspapers of different types are complements.

We also show the importance of allowing for multi-homing readers on the advertising side of the market. Our model of advertising demand allows newspapers to be closer substitutes for advertisers, the more similar they are in terms of reader characteristics, including multi-homing behavior. First, we find that advertisers are more price-sensitive when we account for readers' multi-homing. This is due to the fact that they can reach the same reader through more than one newspaper. Moreover, advertisers' demand is less elastic for newspapers that have a higher share of captive readers, which is consistent with the fact that newspapers offer exclusive access to these readers. In addition, we find that newspapers are closer substitutes for advertisers if they have a higher share of readers in common. When reaching readers in a newspaper becomes more expensive, advertisers will not advertise or advertise less to them in that newspaper and advertise more in other newspapers that those readers buy. Moreover, we find that two of our newspapers are kind of "must-have" for advertisers: if they decide to advertise in national print newspapers, then they first place ads in these two newspapers. This feature is due to their higher circulation and number of captive readers, thus making these outlets more valuable to advertisers. 


\section{Introduction}

Two-sided markets are markets in which firms sell two products or services to two different types of consumers, taking into account that the two demands are linked by indirect network effects. Examples of such markets are media markets, where demand for advertising is related to the size of the audience, and the market for online social networks, where advertising demand depends on the number of users.

A media firm typically operates in a two-sided market as it sells content to readers/viewers and advertising space to advertisers. Moreover, it knows that the size (and possibly the characteristics) of the audience influences the demand for advertising space and, vice versa, the amount (or concentration) of advertising might influence the audience's demand. In other words, a media company recognizes the existence of indirect network effects between the two sides of the market when making its strategic decisions.

With the emergence of digital technologies, multi-homing has become a widespread phenomenon in media markets. In fact, the cost of multi-homing for consumers of media content has dramatically dropped. For instance, newspaper readers can now access multiple online news outlets with just a few clicks, no longer needing to buy and carry a pile of different newspapers, then physically leafing through them. Similarly, TV viewers now have access to many more digital channels. Thus, effectively consumers more frequently multi-home. ${ }^{1}$

Hence, advertisers are now able to reach consumers over a greater number of outlets during their preferred time period (whether a day, a week, or a month). This has implications for the willingness of advertisers to pay for reaching consumers. For instance, considering the extreme case in which an advertiser wishes to reach its target consumers on newspapers only once, the value of second impressions would be zero. In such a case, a merger between newspapers read by two distinct sets of readers (i.e., whose readers single-home) could have very different effects on the prices charged to advertisers than a merger of newspapers with perfectly overlapping readers (i.e., whose readers multi-home). Thus, allowing for multi-homing is crucial when devising policy decisions, whether in assessing mergers among media outlets, in regulating cross-ownership of media, or in setting advertising limits.

We empirically study the role of multi-homing in two-sided markets. First, we build a micro-founded structural econometric model, encompassing demand for differentiated products on both sides of the market and allowing for multi-homing on each side. We then estimate the model using data covering Italian daily newspapers, alternatively taking into account and not taking into account information on multi-homing by readers. Readers' demand is estimated using a nested logit model, where the structure of the nests draws on the traditional classification of national daily newspapers between generalist, sport, and financial. We incorporate information on multi-homing by readers by allowing them to choose between bundles of newspapers. We show that not accounting for multi-homing leads to a substantial bias in the estimation of own- and cross-price elasticities on the readers' side of the market. In particular, own-price elasticities are larger when readers' multi-homing is taken into account.

Allowing for multi-homing recognizes that, when the price of one newspaper rises, those readers that actually multi-home on that newspaper may have more and closer substitute bundles to switch to with respect to when they are assumed to single-home. Thus, readers may turn out to be more price-sensitive

\footnotetext{
${ }^{1}$ For evidence on multi-homing in online markets, see Ambrus, Calvano, and Reisinger (2016), p. 190.
} 
when their multi-homing is taken into account.

Furthermore, while newspapers are assumed to be substitutes in the single-homing model, they can be substitutes or complements when multi-homing by readers is taken into account. Indeed, we find that while newspapers of the same type are substitutes, newspapers of different types are complements.

We also show the importance of allowing for multi-homing readers on the advertising side of the market. Our model of advertising demand captures the idea that advertisers first decide on an overall budget to spend on advertising in national print newspapers, then decide how to allocate this budget across newspapers depending on prices and circulation. The model allows newspapers to be closer substitutes for advertisers, the more similar they are in terms of reader characteristics, including multi-homing behavior. First, we find that advertisers are more price-sensitive when we account for readers' multi-homing. This is due to the fact that they can reach the same reader through more than one newspaper. Moreover, advertisers' demand is less elastic for newspapers that have a higher share of captive readers, which is consistent with the fact that the newspapers offer exclusive access to these readers. In addition, we find that newspapers are closer substitutes for advertisers if they have a higher share of readers in common. When reaching readers in a newspaper becomes more expensive, advertisers will not advertise or advertise less to them in that newspaper and advertise more in other newspapers that those readers buy.

Moreover, we find that two of our newspaper are kind of "must-have" for advertisers: if they decide to advertise in national print newspapers, then they first place ads in these two newspapers. This feature is due to their higher circulation and number of captive readers, thus making these outlets more valuable to advertisers. Finally, our model also delivers interesting insights into the pattern of substitutability between newspapers from the perspective of advertisers. The standard substitution effect can be outweighed by a budget effect, leading to negative cross-price elasticities. This is due to the high elasticity of the budget for advertising in national newspapers, which is consistent with them as a whole being subject to substantial competitive pressure from other advertising outlets.

Our paper contributes to the economic literature on two-sided markets, in which empirical work accounting for multi-homing on both sides of the market is still quite scarce (see next section for a discussion). As discussed below, our results are related to the predictions of the theoretical literature on two-sided markets, in particular to those accounting for multi-homing. Moreover, our contribution allows for a better understanding of the implications of multi-homing and, therefore, is useful for competition and regulation authorities seeking to improve their quantitative assessment in cases involving two-sided platforms. Although print newspapers are a classic example of an offline two-sided market, our empirical model should be seen as an approach to studying the role of multi-homing in (non-transaction) platform markets. The methodology can also be applied to other two-sided markets for which data on user multihoming is available. In light of the prevalence and rising importance of multi-sided platforms in digital markets and the pervasiveness of multi-homing by users on online platforms, the results and conclusions from this paper are also relevant in the context of competition policy cases involving online multi-sided platforms.

The paper proceeds as follows. Section 2 discusses the literature on multi-homing in two-sided markets. Section 3 provides an overview of the market for daily newspapers in Italy and the data we use. Section 4 presents a two-sided model of demand allowing for multi-homing on both sides, while we discuss estimation results in Section 5. Section 6 concludes. 


\section{Multi-Homing in Two-Sided Markets}

Following the seminal works of Caillaud and Jullien (2001, 2003), Rochet and Tirole (2002, 2003, 2006), Parker and van Alstyne (2005), and Armstrong (2006), a growing number of papers address the theoretical aspects of two-sided markets, such as Anderson and Gabszewicz (2006) on media markets. Some, including Evans (2003), Wright (2004), Evans and Schmalensee (2007), Filistrucchi, Klein, and Michielsen (2012), and Filistrucchi, Geradin, Van Damme, and Affeldt (2014) focus on competition policy in two-sided markets.

So far, most of the theoretical literature on two-sided markets assumes single-homing on at least one side of the market, most often on the readers'/viewers' side in media markets. In this context, the competitive bottleneck problem of Armstrong (2006) arises, whereby each media outlet is a monopolist over providing access to its exclusive audience and, thus, advertisers must patronize all of them in order to reach all consumers. As discussed in Anderson and Jullien (2015), the theoretical literature has started filling this gap, e.g. Ambrus, Calvano, and Reisinger (2016), Anderson, Foros, and Kind (2018), Athey, Calvano, and Gans (2018), Jeitschko and Tremblay (2020), and Bakos and Halaburda (2020).

The fact that a fraction of consumers patronizes more than one platform changes the model predictions quite dramatically. If advertisers can reach multi-homing consumers on more than one platform, media outlets no longer only compete for consumers on the audience side of the market but also compete for advertisers on the advertising side of the market. In particular, it turns out that "each platform is able to price to advertisers only the value of its exclusive consumers plus the incremental value associated with multi-homing (shared) consumers" (Anderson, Foros, and Kind (2018), p. 35). This so-called "principle of incremental pricing" has important implications for platforms' strategies in terms of pricing, reaction to mergers, and content provision. Our findings are related to some of the empirical predictions of this literature. In particular, our finding that advertisers are more price-sensitive when we account for readers' multi-homing is consistent with the theoretical finding that advertising prices decrease as multi-homing increases (see Athey, Calvano, and Gans (2018) and Jeitschko and Tremblay (2020)).

Moreover, our result on the existence of some newspapers that are "must-have" for advertisers based on their large circulation, but also on their share of captive readers, might be explained with the result of Athey, Calvano, and Gans (2018) that "because duplicated ad impressions are avoided within a publisher, placing ads on only the larger publisher involves less expected waste than when you place ads on the smaller publisher or spread them across publishers." (Athey, Calvano, and Gans (2018), p. 1581). Finally, we confirm the finding of Ambrus, Calvano, and Reisinger (2016) that it is not just the size, but also the composition of the audience that matters. Indeed, our results suggest that the share of captive versus overlapping readers is a key determinant of advertising prices, which may again be related to the incremental pricing principle.

Despite the considerable number of theoretical contributions, empirical work is lagging behind in accounting for multi-homing. Starting from the seminal papers of Rysman (2004) on the market for yellow pages and Kaiser and Wright (2006) on the German magazine market, most empirical contributions assume single-homing on at least one side of the market, typically the audience side. For example Filistrucchi, Klein, and Michielsen (2012) and Affeldt, Filistrucchi, and Klein (2013), while using data on the Dutch daily newspaper market to simulate the unilateral effects of mergers, do not allow for multi- 
homing; similarly for Filistrucchi and Klein (2013). Ivaldi and Muller-Vibes (2018) estimate a two-sided nested logit model of demand for the print media industry in France, but lack information on readers' multi-homing behavior. Song (2021) builds a two-sided model of demand and estimates it on ataset of TV magazines to show the impact of mergers on the pricing structure and on consumer welfare. Like in our case, readers' demand is modelled with a nested logit. However, readers are assumed to single-home.

While Rysman (2007) shows that multi-homing in adoption, but not in usage, is an important feature of the payment card market, Fan (2013) moves a step forward by allowing each household to buy up to two newspapers in the econometric model. Yet, Fan (2013) lacks information on double-readership of newspapers at the household level and, therefore, does not use this information in the estimation. We do have this information at the individual newspaper level and use it to analyze the impact of allowing for multi-homing readers on the empirical results. Gentzkow (2007) develops a methodology that allows for the consumption of two products in order to study competition between print and online newspapers. The same demand model is also applied by Gentzkow, Shapiro, and Sinkinson (2014), who show that advertising competition leads to increased ideological diversity, and by Grzybowski and Verboven (2016), who study substitution between fixed-line and mobile voice access. Unlike Gentzkow (2007), which has individual-level data on readership for a small set of newspapers, we have aggregate data for a larger set of newspapers. Thus, we build a nested logit demand model encompassing the multi-homing of readers by allowing them to choose between bundles of newspapers. With respect to Gentzkow, Shapiro, and Sinkinson (2014), who also analyze the implications of readers' overlap for advertising-market competition, we have more precise information on readership duplication, whereas it is calibrated in their model. Moreover, unlike them, we allow for network effects from advertisers to readers and for readers' heterogeneity. Both Gentzkow, Shapiro, and Sinkinson (2014) and Fan (2013) restrict the products to be substitutes, whereas our model allows for complementarity.Further, Shi (2015) accounts for readers' multi-homing in the estimation of demand for U.S. magazines, finding that advertising prices are related to the share of exclusive versus overlapping readers. However, he has data on readers' multi-homing just for one period, while we have much richer survey data including bi-annual information from 1992 through 2006. A paper by Liu (2018) estimates the effect of consumer multi-homing on prices in the online advertising market. Ivaldi and Zhang (2021) instead build a model that allows for advertisers' multi-homing and use it to simulate the effect of mergers between digital television platforms.

This paper builds on Argentesi and Filistrucchi (2007), where the authors test for market power in the national daily newspaper market in Italy. However, that paper, lacking information on multi-homing, assumes that readers do not multi-home, i.e., that they read only one newspaper. Both the structural econometric model and the estimation are conducted under this assumption. Moreover, the analysis is conducted on a smaller sample of newspapers (i.e., only the national generalist newspapers) and over a shorter time. Finally, their dataset on the advertising side of the market is much less detailed than the one we use in this paper. 


\section{Data}

The dataset contains information on seven national daily Italian newspapers, belonging to three different categories: general interest, sport, and financial newspapers. ${ }^{2}$ The four general interest newspapers are Corriere della Sera, La Repubblica, La Stampa, and Il Giornale. The two sport newspapers are Corriere dello Sport and Gazzetta dello Sport. The financial newspaper is Il Sole 24 Ore. In December 2006, at the end of our sample period, these seven newspapers accounted for more than $40 \%$ of overall circulation of daily newspapers in Italy. ${ }^{3}$ In the sub-market of general interest newspapers, Corriere della Sera and La Repubblica were, and still are, the largest players in terms of circulation. Other newspapers are not included in our dataset because their circulation is mainly regional (e.g. Il Messaggero or $Q N$ ) or much smaller than those in our sample (e.g. Avvenire). As for sport newspapers, Gazzetta dello Sport and Corriere dello Sport are the largest outlets, with more than $80 \%$ of copies in this segment. Finally, $I l$ Sole 24 Ore is by far the main financial paper, retaining more than $80 \%$ of the market segment in terms of copies sold.

On the readers' side, the dataset features monthly observations for each newspaper on each day of the week from 1992 through 2006. Thus, the dataset contains seven observations per month for each newspaper, from the average Monday to the average Sunday in a given month. Market-level data on circulation comes from those collected for advertising purposes by Accertamenti Diffusione Stampa (ADS). ${ }^{4}$ Specifically, we use monthly average printed copies for each day of the week as a proxy for circulation, since information on the number of copies sold on each day of the week is not available in this dataset. Indeed, it is important to have information disaggregated by day of the week because some weekly supplements are bundled with the newspapers only on some days of the week and cover prices vary by day of the week. We collected information from newspaper publishers on the cover prices of the newspapers and on content characteristics such as the dates regular supplements were introduced, the changes of editors, the presence of local news sections, and the dates newspapers' websites were established.

Information on multi-homing by readers (i.e. on how many readers of a given newspaper also read each of the other newspapers) is collected, for advertising purposes, by Audipress in bi-annual surveys. ${ }^{5}$ In particular, the survey asks readers which newspapers they read on an average day. Then, for each newspaper, it computes the number of readers that read only that newspaper as well as the number of readers that also read each of the other newspapers. However, we do not know whether readers of that newspaper, who also read another newspaper, overlap with readers of a third newspaper. Thus, we only refer to double-homing in the following as we cannot identify those readers who read more than two newspapers from the data. Note that, to the extent that they do not carry out additional surveys themselves, this information comprises all that advertisers know about single-homing or multi-homing by readers.

\footnotetext{
${ }^{2}$ This segmentation of the newspaper market has been adopted in several antitrust decisions, both in Italy and across the European Union. See, for instance, Italian case 3354/95 Ballarino vs. Grandi Quotidiani and the European Commission's decisions M.3817 Wegener/PCM/JV and M.1401 Recoletos/Unedisa.

${ }^{3}$ As of 2021 , these seven newspapers still account for $45 \%$ of overall circulation of daily newspapers.

${ }^{4}$ See http://www.adsnotizie.it/.

${ }^{5}$ See http://www.audipress.it/.
} 
Table 1 shows, by newspaper, the percentage of single- and double-homing readers. Depending on the newspaper, an average of between $25 \%$ and $62 \%$ of the readers single-home, i.e., buy only this specific newspaper. Whether readers single-home or double-home also seems to depend on the type of newspaper: while many readers single-home on a general interest newspaper, only $25 \%$ of the readers of the financial newspaper Il Sole 24 Ore single-home. The Table also shows on which newspapers readers double-home. Thus, the second line shows that, on average, $14.9 \%$ and $14.8 \%$ of Corriere's readers also buy Gazzetta dello Sport and La Repubblica, respectively. The sixth line shows that $21 \%$ of Il Sole 24 Ore readers also read Corriere della Sera or La Repubblica. Figure 1 represents the information on the percentage of readers single- and double-homing graphically. There is one column for each newspaper. The dark-blue area at the bottom of each column represents the percentage of single-homing readers, while all colored areas above it represent the percentage of multi-homing of readers of the given newspapers on each of the other newspapers.

Table 1: Percentage of Readers Single- and Double-Homing by Newspaper

\begin{tabular}{lcccccccc}
\hline Newspaper & $\begin{array}{c}\text { Single- } \\
\text { Homing }\end{array}$ & $\begin{array}{c}\text { DH } \\
\text { Cor- } \\
\text { riere }\end{array}$ & $\begin{array}{c}\text { DH } \\
\text { Cor- } \\
\text { riere } \\
\text { Sport }\end{array}$ & $\begin{array}{c}\text { DH } \\
\text { Gazzetta } \\
\text { Sport }\end{array}$ & $\begin{array}{c}\text { DH } \\
\text { Gior- } \\
\text { nale }\end{array}$ & $\begin{array}{c}\text { DH } \\
\text { Repub- } \\
\text { blica }\end{array}$ & $\begin{array}{c}\text { DH Il } \\
\text { Sole }\end{array}$ & $\begin{array}{c}\text { DH } \\
\text { Stampa }\end{array}$ \\
\hline Corriere & 45.8 &. & 4.4 & 14.9 & 5.8 & 14.8 & 10.2 & 4.1 \\
Corriere Sport & 41.5 & 7.8 &. & 29.5 & 3 & 10.8 & 4.5 & 3.1 \\
Gazzetta Sport & 50.1 & 13.1 & 14.7 &. & 3.5 & 8.7 & 5 & 4.9 \\
Giornale & 29 & 20.4 & 5.9 & 13.8 &. & 12 & 12 & 6.9 \\
Repubblica & 51.4 & 14.6 & 6.1 & 9.7 & 3.3 &. & 9.7 & 5.3 \\
Il Sole & 25 & 21.4 & 5.3 & 11.9 & 7.1 & 20.6 &. & 8.6 \\
Stampa & 61.6 & 6.9 & 2.9 & 9.5 & 3.3 & 8.9 & 6.9 &. \\
\hline
\end{tabular}

We report the mean percentage of readers single-homing and double-homing over the years 1992-2006.

On the advertisers' side of the market, the dataset contains market-level data on advertising quantity, prices, and reader characteristics of those same newspapers, with monthly observations for each different day of the week from 1992 through 2006. Data on advertising quantities and advertising prices net of discounts come from the database of Nielsen Media Research, ${ }^{6}$ while data on readers' demographics come from those collected by Audipress. The latter data are collected bi-annually.

Information on the total number of (advertising and non-advertising) pages per newspaper also comes from Nielsen Media Research, while information on the size of a newspaper was collected browsing on the internet. In combination with information on the price of the paper used to print daily newspapers, collected from Camera di Commercio di Milano, this data allows us to calculate the paper input cost per page and per printed copy.

Table 2 presents summary statistics on the variables we use in the estimation of the readers' side of the market. The average daily circulation of the newspapers included in the dataset is about 560,000 copies, while the mean real cover price over the sample period is about 0.96 Euros per copy.

\footnotetext{
${ }^{6}$ Advertising price does not include advertising in supplements but only in the newspaper itself.
} 
Figure 1: Single- and Double-Homing by Newspaper

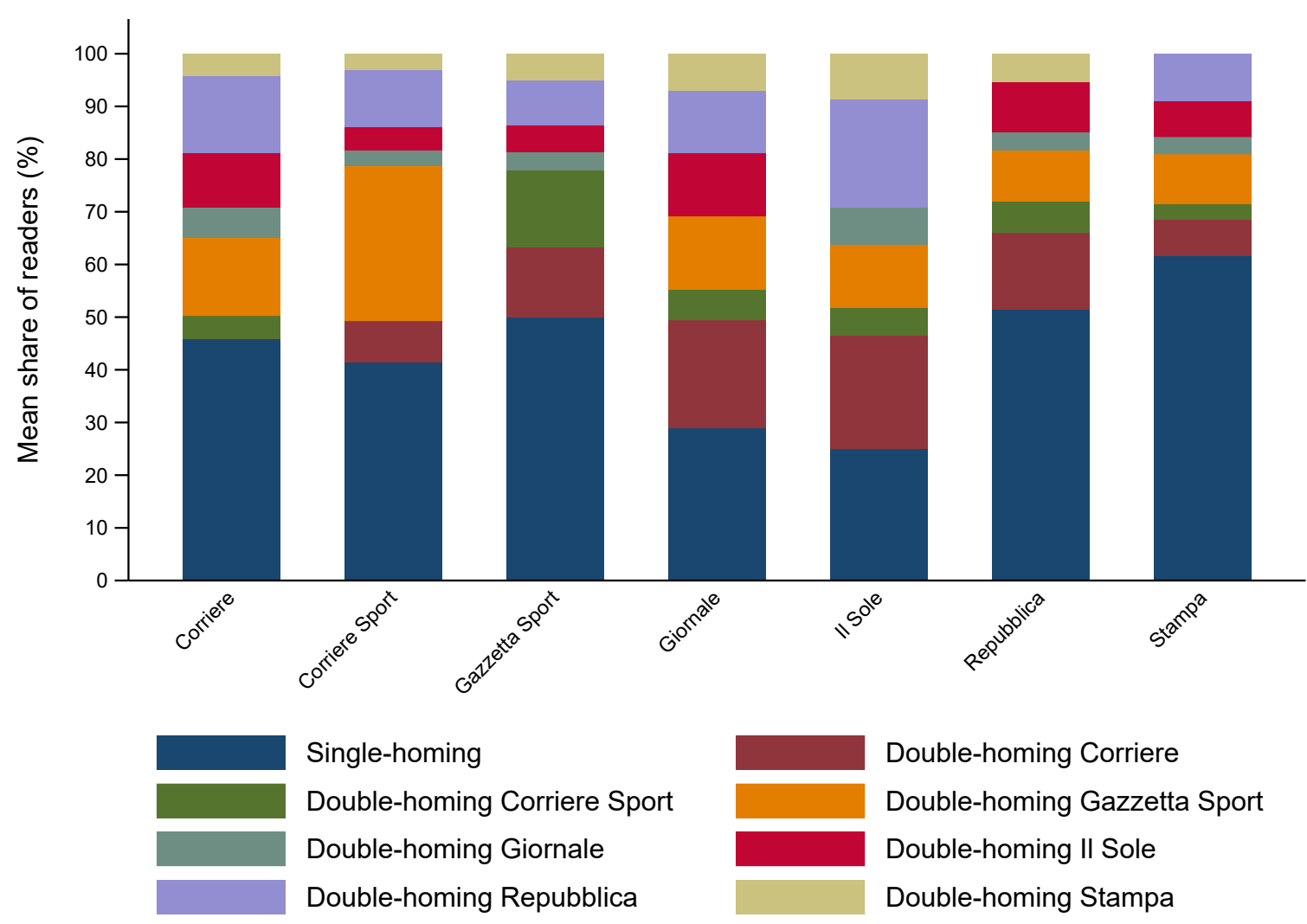

We report the mean percentage of readers single-homing and double-homing over the years 1992-2006.

Table 3 presents instead summary statistics for the variables we use in the estimation of the advertising side of the market. While the mean advertising expenditure share is $14 \%$, the average real advertising price is about 180 Euros per advertising slot.

Importantly, the variable "captive readers" measures the percentage of single-homing readers for each newspaper. This measure is crucial in order to properly account for multi-homing by readers: the more readers single-home, the higher the market power of the newspaper on the advertising side of the market, as newspapers enjoy monopoly power over providing access to these captive readers (see Armstrong, 2006).

Hence, the final datasets both on the reader side as well as on the advertising side of the market cover monthly observations for each different day of the week for the seven newspapers from January 1992 through December 2006. Appendix A.1 contains a list of all the variables used in our empirical analyses together with the corresponding data sources. 
Table 2: Summary Statistics Reader Side (1992-2006)

\begin{tabular}{lcccc}
\hline & & & & \\
& mean & sd & $\min$ & $\max$ \\
\hline Average newspaper's prints (10k) & 56.76 & 20.19 & 21.12 & 127.43 \\
Market share (\%) & 1.14 & 0.41 & 0.43 & 2.60 \\
Real cover price (EUR/copy) & 0.96 & 0.12 & 0.79 & 1.60 \\
Number of pages & 40.43 & 13.00 & 16.50 & 115.00 \\
Number of advertising slots (k) & 0.94 & 0.51 & 0.05 & 3.34 \\
Advertising intensity (slots/pages) & 22.58 & 8.23 & 1.81 & 51.99 \\
Generalist magazine & 0.56 & 0.50 & 0.00 & 1.00 \\
Generalist magazine (day) & 0.07 & 0.26 & 0.00 & 1.00 \\
Women magazine & 0.21 & 0.40 & 0.00 & 1.00 \\
Women magazine (day) & 0.03 & 0.17 & 0.00 & 1.00 \\
Economic insert & 0.29 & 0.45 & 0.00 & 1.00 \\
Economic insert (day) & 0.04 & 0.20 & 0.00 & 1.00 \\
Local pages & 5.45 & 5.64 & 0.00 & 22.00 \\
Website & 0.50 & 0.50 & 0.00 & 1.00 \\
Real paper cost (EUR/copy) & 0.11 & 0.04 & 0.04 & 0.32 \\
\hline Observations & 8795 & & & \\
\hline
\end{tabular}

Table 3: Summary Statistics Advertiser Side (1992-2006)

\begin{tabular}{lcccc}
\hline & & & & \\
& mean & sd & min & max \\
\hline Advertising expenditure share (\%) & 14.33 & 10.18 & 0.36 & 51.05 \\
Real advertising slot price (k EUR) & 0.18 & 0.09 & 0.03 & 0.59 \\
Percentage of readers between 14 and 17 & 4.76 & 2.88 & 0.84 & 12.87 \\
Percentage of readers between 18 and 24 & 13.03 & 4.23 & 5.40 & 21.68 \\
Percentage of readers between 25 and 34 & 21.51 & 3.23 & 15.90 & 30.40 \\
Percentage of readers between 35 and 44 & 19.45 & 2.78 & 13.70 & 26.60 \\
Percentage of readers between 45 and 54 & 17.36 & 2.59 & 11.78 & 23.40 \\
Percentage of readers between 55 and 64 & 12.57 & 2.57 & 7.30 & 18.83 \\
Percentage of readers above 65 & 11.31 & 4.91 & 3.20 & 23.60 \\
Percentage of readers in low income group & 12.71 & 7.27 & 2.90 & 32.20 \\
Percentage of readers in middle income group & 61.36 & 4.88 & 49.25 & 72.20 \\
Percentage of readers in high income group & 25.93 & 9.92 & 9.03 & 46.60 \\
Percentage of female readers & 31.64 & 12.27 & 9.00 & 46.50 \\
Percentage of captive readers & 43.47 & 12.81 & 9.49 & 66.50 \\
\hline Observations & 8795 & & & \\
\hline
\end{tabular}




\section{A Model of Demand}

The structural econometric model encompasses demand for differentiated products on both sides of the market and allows for multi-homing on each side of the market. We estimate both readers' demand and advertisers' demand taking into account the inter-market network effects that characterize two-sided markets.

On the readers' side of the market, demand derives from random utility maximization by readers and is estimated using a nested logit model, as in Berry (1994). The structure of the nests draws on the traditional classification of national daily newspapers into generalist, sport, and financial. On this side of the market, we have information on multi-homing. When taking into account this information, readers are allowed to choose between all possible newspaper-pairings and nests are designed accordingly as pairs of newspapers of the same or of different categories.

On the advertisers' side of the market, demand derives from advertisers' choice to allocate a given advertising budget, which is affected by the business cycle, across different newspapers. This is similar to consumers allocating a given budget among different types of beers as in Hausman, Leonard, and Zona (1994). Product differentiation is interpreted in the spatial sense proposed by Pinkse, Slade, and Brett (2002), as applied parametrically in Slade (2004) and in Pinkse and Slade (2004). Hence, cross-price elasticities among two products (in our case advertising slots in two different newspapers) are assumed to be a function of the distance among the products in characteristic space, so that cross-price elasticities would be higher when products are closer to each other in terms of characteristics. In our application, the distance metrics are derived from differences among newspapers in the demographic characteristics of readers. In addition, own-price effects are allowed to depend on readers' characteristics. While our model also allows for advertisers to multi-home, we do not have, and hence do not use, data on multihoming by advertisers. However, consistently with the theoretical models of two-sided markets, the information on multi-homing by readers can be used also in the estimation of advertising demand. In particular, we derive distance metrics from the number of overlapping readers between two newspapers, and the number of captive readers is considered as an additional newspaper characteristic from the point of view of advertisers. Finally, in applying the distance metrics model to a two-sided market such as the newspaper market, we allow advertising demand on a newspaper to depend on its circulation.

\subsection{Readers' Demand}

On the readers' side of the market, demand derives from random utility maximization by readers and is estimated using a nested logit model as in Berry (1994). ${ }^{7}$ Hence, reader $i$ at time $t$ on weekday $d$ chooses one unit of newspaper $j \in J$ to maximize utility

$$
u_{i j t d}=\alpha p_{j t d}+\beta x_{j t d}+\gamma a_{j t d}+\xi_{j t d}+\zeta_{g t d}+(1-\sigma) \varepsilon_{i j t d},
$$

where $p_{j t d}$ is the real cover price of newspaper $j$ at time $t$ on weekday $d, x_{j t d}$ is a set of observed newspaper characteristics, $a_{j t d}$ is the advertising intensity in newspaper $j$ at time $t$ on weekday $d$ (mea-

\footnotetext{
${ }^{7}$ We also estimated a random coefficient logit model. However, the random coefficient for the cover price is not estimated to be significant. Further, Fan (2013) also finds that consumer heterogeneity in price sensitivity is very small and statistically insignificant. Therefore, she also refrains from estimating a random coefficient on newspaper subscription price.
} 
sured as advertising slots per page), $\xi_{j t d}$ is an unobserved (by the econometrician) product characteristic, $\zeta_{g t d}$ represents consumer utility common to all newspapers of nest $g$ at time $t$ on weekday $d$, and $\varepsilon_{i j t d}$ is an idiosyncratic error term assumed to be i.i.d. extreme value type 1. $\sigma$ measures the correlation of unobserved utility between newspapers within nests relative to the between ones. As $\sigma$ approaches one, newspapers within a nest approach being perfect substitutes, if $\sigma$ is instead equal to zero, the correlation of unobserved utility within nests is zero and we are back to the simple logit case.

The structure of the nests draws on the traditional classification of national daily newspapers into generalist, sport, and financial newspapers. As discussed in Section 3, we have data on four general interest newspapers, two sport newspapers, and one financial newspaper. Figure 2 in Appendix A.3 shows the structure of the nests under the single-homing assumption.

The resulting baseline estimation equation of the nested logit model is the following:

$$
\ln \left(s_{j t d}\right)-\ln \left(s_{0 t d}\right)=\alpha p_{j t d}+\beta x_{j t d}+\gamma a_{j t d}+\sigma \ln \left(s_{j t d \mid g}\right)+\phi_{j d}+\tau_{t g}+v_{j t d},
$$

where $s_{j t d}$ is the market share of newspaper $j$ at time $t$ on weekday $d, s_{0 t d}$ is the market share of the outside good, $p_{j t d}$ is the newspaper's cover price, $x_{j t d}$ is a set of observed newspaper characteristics, $a_{j t d}$ is the advertising intensity in newspaper $j$, and $s_{j t d \mid g}$ is the share of newspaper $j$ within nest $g$. We split the unobserved product characteristic $\xi_{j t d}$ into the newspaper-weekday fixed effect $\phi_{j d}$, the time fixed effects $\tau_{t g}$, and the i.i.d. error term $v_{j t d}$.

The newspaper-weekday fixed effects capture the unobserved product characteristics that are constant over time. The time fixed effects, specific to each nest, capture variations in time in the relative attractiveness of the outside good with respect to the different categories of newspapers in our sample (for instance because of the appearance of internet, which is here allowed to have differential effects on sales of sport, business, and generalist newspapers). We further control for seasonality (see Section 5 for details). The market shares are defined over the total potential market size, which is considered to be the total population in Italy older than 14 years, as is usual in studies on media markets.

The newspaper cover price, the advertising intensity, as well as the within nest market share are all endogenous as they might be correlated with the unobserved product characteristic $\xi_{j t d}$. Following Berry, Levinsohn, and Pakes (1995) and Nevo (2000), we use the sum of the characteristics of the other newspapers as instruments for the newspaper cover price (so called 'BLP instruments'). Specifically, we use the dummy variables for the weekday when a supplement is bundled to the newspaper, when a women magazine is bundled to the newspaper, as well as the number of local pages to construct the BLP instruments for newspaper cover price. The within nest market share is instrumented with the corresponding BLP instruments within a given nest. As described in Section 3, we also construct a marginal cost measure, the real paper cost per copy, which varies over newspapers and over time, that is used as an instrument for cover price and advertising intensity. The reasoning behind the use of this instrument is that if the paper cost per issue increases, the cover price increases, thus readers decrease. The newspaper then increases the advertising intensity by decreasing the ad price. ${ }^{8}$ Lastly, we use Italian GDP to instrument advertising intensity, as GDP is a measure of the overall business cycle and advertising expenditures by companies increase with the business cycle, whereas, given the low price for

\footnotetext{
${ }^{8}$ Indeed, in the first stage for advertising intensity, the cost per issue is positive and significant.
} 
a copy of a newspaper, income effects from the business cycle are not expected to be substantial and not to directly affect readers' demand. ${ }^{9}$

We aim to investigate the bias that can take place in the estimation of demand parameters, in particular price elasticities and indirect network effects, when neglecting readers' multi-homing. In order to assess the relevance of this bias, we estimate two different specifications of readers' demand. The traditional demand equation (similar to Argentesi and Filistrucchi (2007)) assumes that readers only read one newspaper in each period, i.e. all readers single-home. Therefore, we estimate the nested logit model at the newspaper level: $j$ in equations (1) and (2) refers to a newspaper. We also estimate a second, alternative demand equation where readers are allowed to read up to two newspapers (which is what we observe in the data). Thus, we model readers as choosing between all possible newspaper-pairings (including single-homing on a newspaper) and estimate readers' demand at the bundle level. ${ }^{10}$ This implies that $j$ in equations (1) and (2) now refers to a bundle of up to two newspapers. Nests are accordingly designed at the bundle level. Consistent with the structure of nests under the single-homing assumption, under the double-homing assumption we distinguish six nests, comprising respectively: general interest newspaper bundles, sport newspaper bundles, financial newspaper bundles, general interest/sport bundles, general interest/financial bundles, and sport/financial bundles. Figure 3 in Appendix A.3 shows the structure of the nests under the double-homing assumption.

Estimating the nested logit discrete choice model at the bundle level relaxes the strong assumption of all newspapers being substitutes. While a discrete choice model at the bundle level still assumes that newspaper bundles are substitutes, individual newspapers can be complements rather than substitutes. ${ }^{11}$

The own-price elasticity of demand $\eta_{j j}$ in the nested logit model is given by (for $\alpha>0$ ):

$$
\eta_{j j}=\frac{\partial s_{j t}}{\partial p_{j t}} \frac{p_{j t}}{s_{j t}}=-\frac{\alpha}{1-\sigma} p_{j t}\left[1-(1-\sigma) s_{j t}-\sigma s_{j t \mid g}\right]
$$

The cross-price elasticities of demand $\eta_{j k}$ are instead given by (for $\alpha>0$ ):

$$
\eta_{j k}=\frac{\partial s_{j t}}{\partial p_{k t}} \frac{p_{k t}}{s_{j t}}= \begin{cases}\alpha p_{k t}\left[s_{k t}+\frac{\sigma}{1-\sigma} s_{k t \mid g}\right] & \text { if } k \neq j \text { and } k \in g \\ \alpha p_{k t} s_{k t} & \text { if } k \neq j \text { and } k \notin g\end{cases}
$$

Note that, when readers' demand is estimated at the bundle level, the above elasticity formulas give the own-price and cross-price elasticities at the bundle rather than at the newspaper level. However, we are ultimately interested in the elasticities at the newspaper level. Hence, when computing elasticities, we first compute the marginal effects at the bundle level, sum up all the relevant marginal effects at the bundle level to get to the marginal effects at the newspaper level, and then multiply these marginal effects

\footnotetext{
${ }^{9}$ See for example van der Wurff, Bakker, and Picard (2008) for an empirical study on the link between economic growth, measured by GDP, and advertising intensity and expenditures for different media and in different industrialized countries. In particular, the results show that advertising expenditures in newspapers respond, relatively closely, to economic change, while the link is weaker for TV, radio, and cinema. The paper also contains a comprehensive review of the existing literature establishing the relationship between advertising spending and economic growth.

${ }^{10}$ Thus, we construct a second dataset based on the data on multi-homing behavior of readers, in which the level of observation is no longer a newspaper but a bundle of up to two newspapers for a given weekday and month. Appendix A.2 contains a detailed description of how we construct the dataset at the bundle level based on the newspaper level data and on the survey information on multi-homing by readers.

${ }^{11}$ In particular, as the utility is parametrized at the bundle level, the $\Gamma_{A B}$ in Gentzkow (2007), which determines whether goods $A$ and $B$ are substitutes or complements, can be negative or positive. However, we do not estimate the $\Gamma$ s explicitly.
} 
with the respective newspaper price (own or cross) and divide by the newspaper's market share to obtain the elasticities at the newspaper level.

\subsection{Advertisers' Demand}

On the advertisers' side of the market, we depart from the modeling choices of the previous literature. Many papers use very stylized models on the advertising side of the market. For example, Argentesi and Filistrucchi (2007) use a logit model for advertisers' demand, which assumes that advertisers make the discrete choice of placing ads in one newspaper only. Secondly, in this model, substitution between newspapers is proportional to newspapers' market shares. Other studies, such as for example Rysman (2004) or Shi (2015), estimate inverse advertising demand, where advertising price is a function of advertising quantity, the number of readers (potentially distinguishing captive and multi-homing readers) and fixed effects. However, this assumes that advertising in different newspapers are independent goods for advertisers.

Our model of advertising demand tries to capture the following ideas of how advertising demand works in practice: advertisers first decide on an overall budget to spend on advertising in national print newspapers (relative to other channels). They then decide how to allocate this budget across newspapers depending on the respective advertising prices and circulation of newspapers. ${ }^{12}$ Thus, advertisers' demand is continuous and advertisers can multi-home: they decide how many advertising slots to buy in each newspaper and they can potentially advertise in all newspapers at the same time. Lastly, the model tries to capture the idea that newspapers are closer substitutes for advertisers, the more similar these newspapers are in terms of reader characteristics.

Although our empirical specification of advertisers' demand is somewhat targeted to our specific context, it is still relevant for online platforms. Even in an online context, it is likely that advertisers first set a budget for online advertising and then decide how to split the budget across outlets. Furthermore, how close substitutes outlets are from an advertiser's view should be a function of viewers/readers reached via the different outlets. Even though one would expect that, in an online context, more sophisticated consumer characteristics matter for advertising, actually the most popular digital information bought by the majority of advertisers is basic demographic data on age and gender (Neumann, Tucker, and Whitfield, 2019).

Thus, on the advertisers' side of the market, demand derives from advertisers' choice to allocate a given budget, which changes with the business cycle, across different media outlets. This approach follows Hausman, Leonard, and Zona (1994), who model consumer choices among different brands of beer. Product differentiation is interpreted in the spatial sense proposed by Pinkse, Slade, and Brett (2002), as applied parametrically in Slade (2004) and in Pinkse and Slade (2004). The basic idea is that cross-price elasticities among two products (in our case advertising slots in two different newspapers) should be a function of the distance among the products in characteristic space. One would then expect higher cross-price elasticities when products are closer to each other in terms of characteristics. In addition, own-price effects are allowed to depend on characteristics of the newspapers. In our case,

\footnotetext{
${ }^{12} \mathrm{We}$ abstract from the role of intermediaries, assuming that the advertising agencies act in the interest of advertisers and, therefore, base their choices on price and circulation.
} 
the distance metrics are derived from differences among newspapers in the demographic characteristics of readers (e.g., age, gender, income) and from the number of overlapping readers between the two newspapers, while the own-price elasticities are allowed to depend on the number of captive readers. As required by the two-sidedness of the media market, we allow advertising demand on a newspaper to depend on its circulation. In the demand specification, the circulation of the newspapers is treated the same way product advertising is treated in Rojas (2008) and Rojas and Peterson (2008), by allowing own-circulation effects to depend on product characteristics and cross-circulation effects to depend on the distance between newspapers in characteristic space.

Following Hausman, Leonard, and Zona (1994), advertising demand is estimated using demand equations at different levels. At the top level, advertisers decide on a budget to spend on advertising in our set of national print newspapers (relative to advertising via other channels). The estimation equation of overall demand for advertising space on national newspapers is the following:

$$
\ln \left(q_{t d}\right)=\beta_{0}+\beta_{1} \ln \left(y_{t}\right)+\beta_{2} \ln \left(P_{t d}\right)+\phi Z_{t d}+\varepsilon_{t d}
$$

where $q_{t d}$ is total advertising quantity (measured in advertising slots) at time $t$ on weekday $d, y_{t}$ is GDP at time $t, P_{t d}$ is a deflated price index for advertising in newspapers at time $t$ on weekday $d$ (see explanation on the price index below), $Z_{t d}$ is a set of time and seasonal controls, potentially different by weekday, and $\varepsilon_{t d}$ is an i.i.d. error term varying across time and weekday. Hence, the coefficient $\beta_{2}$ on the price index for advertising in newspapers is the overall price elasticity of advertising demand in these seven newspapers relative to other media outlets.

The endogenous advertising price index $P_{t d}$ is instrumented by printing cost shifters, in particular the average real paper cost per page (averaged across the seven newspapers), an electricity price index for industrial consumers, ${ }^{13}$ and an hourly wage index for the printed media sector.

At the newspaper level, advertisers decide in a second step on how to allocate their newspaper advertising budget chosen at the top level across the seven newspapers. Thus, advertisers are allowed to multi-home and can potentially decide to buy (different amounts of) advertising space in all of the seven newspapers at the same time.

Following Rojas (2008) and Rojas and Peterson (2008), we use a linear approximation of the Almost Ideal Demand System by Deaton and Muellbauer (1980) to model newspaper level advertising demand. The estimation equation of demand for advertising space in a particular newspaper is then:

$$
w_{j t d}=f_{j t d}+\sum_{k=1}^{J} b_{j k t} \ln \left(p_{k t d}\right)+\sum_{k=1}^{J} c_{j k t} \ln \left(\operatorname{cir}_{k t d}\right)+d_{j} \ln \left(\frac{x_{t d}}{P_{t d}}\right)+\varepsilon_{j t d},
$$

In equation (6), $w_{j t d}$ is the advertising sales share of newspaper $j$ at time $t$ on weekday $d$ (i.e. $\left.w_{j t d}=\frac{p_{j t t} q_{j t d}}{x_{t d}}\right)$. The term $f_{j t d}$ can incorporate time and newspaper dummy variables, newspaper characteristics and market-specific variables such as demographics. $p_{k t d}$ is the real price per advertising slot in newspaper $k$ at time $t$ on weekday $d, \operatorname{circ}_{k t d}$ is the circulation of newspaper $k$ at time $t$ on weekday $d, x_{t d}$ is total advertising expenditures at time $t$ on weekday $d$ (i.e. $x_{t d}=\sum_{j=1}^{J} p_{j t d} q_{j t d}$ ), and $P_{t d}$ is an overall

\footnotetext{
${ }^{13}$ series nrg_pc_205_h, consumption band Ie from Eurostat.
} 
advertising price index. ${ }^{14}$ Rojas and Peterson (2008) use a Laspeyres index for the overall advertising price index defined as $\ln \left(P_{t d}^{L}\right)=\sum_{j=1}^{J} w_{j}^{0} \ln \left(p_{j t d}\right)$, with $w_{j}^{0}$ being the base share of newspaper $j$, defined as $w_{j}^{0}=\frac{1}{7 T} \sum_{t=1}^{T} \sum_{d=1}^{7} w_{j t d}$. However, in our dataset, some of the newspapers are not available on all weekdays in the earlier years of the data. Using the base share $w_{j}^{0}$ of newspapers to compute the overall advertising price index would, thus, artificially understate the price index for those weekday observations when not all seven newspapers are available. Therefore, we use the Stone price index to measure the overall advertising price instead, defined as $\ln \left(P_{t d}\right)=\sum_{j=1}^{J} w_{j t d} \ln \left(p_{j t d}\right)$, as has been proposed by Deaton and Muellbauer (1980) and often applied in practice. The term $\ln \left(\frac{x_{t d}}{P_{t d}}\right)$ enters the estimation equation as the advertising sales shares are conditional on the total advertising expenditures $x_{t d}$ set at the top level, i.e. holding total advertising expenditures $x_{t d}$ constant.

Equation (6) is a first-order approximation in prices and circulation to a demand function allowing for unrestricted price and circulation parameters. In order to reduce the number of cross-price and crosscirculation coefficients that need to be estimated, following Slade (2004) and Pinkse and Slade (2004), we model the cross-price and cross-circulation coefficients $b_{j k t}$ and $c_{j k t}$ as linear functions of distance measures between newspapers $j$ and $k$. In particular, how close substitutes two newspapers are in the eyes of advertisers depends on how close these two newspapers are in characteristics space. The closeness metrics are derived from differences among newspapers in the demographic characteristics of readers (age, gender, income) and the number of overlapping readers between the two newspapers.

Thus, the estimation equation becomes:

$w_{j t d}=f_{j t d}+b_{j j t} \ln \left(p_{j t d}\right)+c_{j j t} \ln \left(\operatorname{circ}_{j t d}\right)+\sum_{k \neq j}^{J} g\left(\delta_{j k t}\right) \ln \left(p_{k t d}\right)+\sum_{k \neq j}^{J} h\left(\mu_{j k t}\right) \ln \left(\operatorname{circ}_{k t d}\right)+d_{j} \ln \left(\frac{x_{t d}}{P_{t d}}\right)+\varepsilon_{j t d}$,

with

$$
\begin{gathered}
b_{j k t}=g\left(\delta_{j k t}\right)=\sum_{l=1}^{L} \lambda_{l} \delta_{j k t}^{l} \\
c_{j k t}=h\left(\mu_{j k t}\right)=\sum_{m=1}^{M} \tau_{m} \mu_{j k t}^{m}
\end{gathered}
$$

Where $\delta_{j k t}$ and $\mu_{j k t}$ are the $L$ and $M$ closeness measures that determine the cross-price and crosscirculation effects, respectively, while $\lambda_{l}$ and $\tau_{m}$ are parameters to be estimated.

Substituting (8) and (9) into (7) and regrouping terms, the estimation equation is given by:

$w_{j t d}=f_{j t d}+b_{j j t} \ln \left(p_{j t d}\right)+c_{j j t} \ln \left(\operatorname{circ}_{j t d}\right)+\sum_{l=1}^{L} \lambda_{l} \sum_{k \neq j}^{J} \delta_{j k t}^{l} \ln \left(p_{k t d}\right)+\sum_{m=1}^{M} \tau_{m} \sum_{k \neq j}^{J} \mu_{j k t}^{m} \ln \left(\operatorname{circ}_{k t d}\right)+d_{j} \ln \left(\frac{x_{t d}}{P_{t d}}\right)+\varepsilon_{j t d}$

\footnotetext{
${ }^{14}$ On the readers' side of the market, we include advertising in readers' demand as advertising intensity $a_{j t d}$. Advertising intensity is defined as the number of advertising slots divided by the number of pages of newspaper $j$ at time $t$ on weekday $d$. This relates to the advertising sales share $w_{j t d}$ as this share is defined as advertising expenditures on newspaper $j$ divided by total advertising expenditures $x_{t d}$ at time $t$ on weekday $d$, where expenditures are price times quantity and advertising quantity is measured in advertising slots. Newspaper circulation included in advertisers' demand relates to the readers' demand market share $s_{j t d}$ as $s_{j t d}=\frac{\text { circulation }_{j t d}}{\text { totalmarketsize }_{t d}}$.
} 
The closeness measures between newspapers for continuous product characteristics use an inverse measure of Euclidean distance. ${ }^{15}$ These closeness measures between two newspapers vary between zero and one, so that a one implies that the two newspapers are at the same location in characteristic space. For discrete closeness measures (for example the type of newspaper: generalist, sport, financial), the closeness between two newspapers is equal to one if they belong to the same group (i.e., are of the same type) and zero otherwise. The cross-price and cross-circulation coefficients $b_{j k t}$ and $c_{j k t}$ are then recovered by replacing the estimated coefficients $\lambda_{l}$ and $\tau_{m}$ and the closeness measures $\delta_{j k t}$ and $\mu_{j k t}$ into (8) and (9), respectively. See Appendix A.4 for further details on the computation of closeness measures.

Note that also the own-price and own-circulation coefficients $b_{j j t}$ and $c_{j j t}$ can be modeled as functions of newspaper $j$ 's own product characteristics. For example, using the percentage of female readers as the relevant product characteristic, the own-price coefficient in (8) would be defined as $b_{j j t}=$ $b_{1}+b_{2}$ femalereaders $_{j t}$, where femalereaders $j$ is the percentage of female readers of newspaper $j$ at time $t$.

Since we specifically aim to investigate the effect of reader multi-homing on the estimation of demand parameters on both sides of the market, we model the own-price effects as a function of the percentage of captive readers a newspaper has and the cross-price effects as a function of the overlap in readers between two newspapers. Like the estimation of readers' demand, we estimate two specifications, one disregarding multi-homing information, such as the percentage of captive readers or the percentage of overlapping readers, and one using this information. Note that we treat the number of captive and joint readers as exogenous when estimating advertising demand. The reason for this is that, first, the survey information on reader demographics, including on multi-homing behavior, is collected bi-annually. To the extent that they do not carry out additional surveys themselves, advertisers can be expected to base their advertising decisions on this demographic information for a period of six month. Thus, in the estimation, this information is predetermined. Secondly, we do not estimate random effects on the reader side of the market. Hence, in a potential simulation exercise, there will be no changes in the composition of readers following price increases.

There are different possibilities to model the budget effect, i.e., the effect of a change in total advertising expenditures $x_{t d}$ on newspaper level demand. In equation 7, this effect is captured by $d_{j}$, the coefficient on $\ln \left(\frac{x_{t d}}{P_{t d}}\right)$ that links the top level with the newspaper level demand. One possibility is to interact $\ln \left(\frac{x_{t d}}{P_{t d}}\right)$ with newspaper dummy variables, as the effect of a change in total advertising expenditures $x_{t d}$ can affect the sales shares $w_{j t d}$ differently for each newspaper: for some newspapers, an increase in total advertising expenditures on national print newspapers will increase their advertising sales more than proportionally, for other newspapers, the increase can be less than proportional. Specifying the $d_{j}$ as newspaper dummy variables also provides a natural specification test. Since $w_{j t d}$ is the advertising sales share of newspaper $j$ out of all newspapers, the advertising sales shares add up to one across newspapers. This implies that if $w_{j t d}$ increases for some newspapers following an increase in total advertising expenditures $x_{t d}$, the sales share of some other newspaper must decrease, i.e., the newspaper specific coefficients must add up to zero $\left(\sum_{j=1}^{J} d_{j}=0\right)$. If this is not the case, the model is misspecified. Another possibility is to specify $d_{j}$ as a function of newspaper characteristics, where this function can

\footnotetext{
${ }^{15}$ In particular, the closeness between newspapers $j$ and $k$ in terms of product characteristic $x$ is defined as $\frac{1}{1+2 \sqrt{\left(x_{j}-x_{k}\right)^{2}}}$.
} 
be specified in such a way that the restriction on the sum of the effects across newspapers adding up to zero holds by construction. In particular, we construct newspaper/weekday-specific $d_{j}$ s as the mean newspaper/weekday-specific characteristic minus the weekday-specific mean of this characteristic across newspapers. ${ }^{16}$ Constructing the $d_{j}$ s in this way implies that the sum of the effects across newspapers is zero by construction on each day of the week. Another advantage of making $d_{j}$ a function of newspaper characteristics is that it allows for studying which newspaper characteristics actually influence the link between total advertising expenditure $x_{t d}$ and the newspapers' advertising sales shares $w_{j t d}$.

Advertising prices as well as newspaper circulation are endogenous and must be instrumented for in the estimation. Following Slade (2004), we use product characteristics of competing newspapers as instruments for price (i.e. BLP instruments). In particular, we use the sum across competitors of the percentage of female readers as well as the mean age of readers to instrument for own advertising price. In addition, we use the cost shifter real paper cost per page to instrument own advertising price. Newspaper circulation is instrumented with the real paper cost per issue as well as the dummy for the day of the week when a magazine of general information is bundled with the newspaper. Increases in the printing costs should increase the newspaper price and, hence, decrease reader demand, while adding a magazine to the newspaper increases reader demand (see estimation results on readers' demand in Section 5). Using the dummy for a magazine of general information as instrument for circulation relies on the assumption that the presence of the magazine does not directly influence the demand for advertising space on the newspaper (other than through its effect on newspaper circulation). Lastly, as total advertising expenditures $x_{t d}$ are constructed from prices and quantity variables, they are also treated as endogenous and instrumented with GDP.

The price elasticities of advertising demand $\tilde{\eta}_{j k}$ conditional on total advertising expenditures $x_{t d}$ are given by:

$$
\tilde{\eta}_{j k}= \begin{cases}-1+\frac{b_{j j t}}{w_{j t}}-d_{j} & \text { if } k=j \\ \frac{b_{j k t}}{w_{j t}}-d_{j} \frac{w_{k t}}{w_{j t}} & \text { if } k \neq j\end{cases}
$$

with $b_{j j t}$ potentially being a function of own product characteristics and $b_{j k t}$ being a function of the closeness measures.

Unconditional advertising price elasticities also need to account for how advertising price increases by one newspaper change the overall price index for advertising in newspapers, how this in turn then changes the overall demand for advertising in print newspapers at the top level relative to other media outlets (overall elasticity of advertising demand in national newspapers), and how this change in total advertising expenditures $x_{t d}$ then affects the advertising quantity demanded on newspaper $j$ (budget effect). The unconditional price elasticities for advertising demand $\eta_{j k}$ take these effects into account and are given by:

\footnotetext{
${ }^{16}$ For example, if the respective newspaper characteristic is the newspaper circulation, the measure $d_{j d}$ for Corriere della Sera on Mondays would be defined as the mean circulation of Corriere della Sera on Mondays minus the mean newspaper circulation on Mondays across all seven newspapers, i.e. $d_{j d}=\frac{1}{T} \sum_{t=1}^{T}$ circulation $_{j t d}-\frac{1}{J T} \sum_{t=1}^{T} \sum_{j=1}^{J}$ circulation $_{j t d}$. This implies that the circulation related measures add up to zero across newspapers for each day of the week.
} 


$$
\eta_{j k}= \begin{cases}\tilde{\eta}_{j j}+\left(1+\frac{d_{j}}{w_{j t}}\right)\left(\beta_{2}+1\right) w_{j t} & \text { if } k=j \\ \tilde{\eta}_{j k}+\left(1+\frac{d_{j}}{w_{j t}}\right)\left(\beta_{2}+1\right) w_{k t} & \text { if } k \neq j\end{cases}
$$

where $\beta_{2}$ is the overall price elasticity of advertising demand in the seven newspapers relative to other media outlets estimated at the top level (see equation (5)). Since the second term in equation 12 can be negative and larger in absolute value than the conditional cross-price elasticities $\tilde{\eta}_{j k}$, unconditional cross-price elasticities $\eta_{j k}$ can be negative, even though newspapers are substitutes for advertisers (more or less close depending on reader characteristics). The negative budget effect depends on the size of the newspaper in terms of advertising sales share. If a large newspaper increases its advertising price, the impact on the overall price index for advertising in newspapers is relatively large. In turn, this will lead to a relatively large decrease in total advertising expenditures $x_{t d}$ at the top level, which lowers advertising demand on each newspaper $j$ (more or less than proportional). If this effect is larger than the substitution effect, cross-price elasticities turn negative.

The circulation elasticities of advertising demand $\rho_{j k}$, which do not depend on total advertising expenditures $x_{t d}$, are given by:

$$
\rho_{j k}= \begin{cases}\frac{c_{j j t}}{w_{j t}} & \text { if } k=j \\ \frac{c_{j k t}}{w_{j t}} & \text { if } k \neq j\end{cases}
$$

with $c_{j j}$ potentially being a function of own product characteristics and $c_{j k}$ being a function of the closeness measures.

Appendix A.5 contains the derivation of both the conditional and the unconditional price as well as the circulation elasticities.

\section{Estimation Results}

\subsection{Readers' Demand}

\subsubsection{Estimation Results}

We present here the results on the estimation of readers' demand, once under the assumption of singlehoming readers (nested logit at newspaper level) and once under the assumption of double-homing readers (nested logit at bundle level).

The first two specifications in Table 4 show results for readers' demand assuming single-homing by readers. The last two columns report instead the specifications that allow for double-homing readers. All specifications contain nest-specific (i.e. newspaper-type or bundle-type) year fixed effects to account for the time trend as well as nest-specific month fixed effects to account for seasonality. ${ }^{17}$

Let us first consider the single-homing specifications. The price coefficient is negative and statistically significant. The marginal effect suggests that a cover price increase of 10 cents decreases circulation by between $48 \mathrm{~K}$ and $126 \mathrm{~K}$ readers depending on the newspaper. The advertising intensity coefficient is positive and significant in the baseline specification of column (1). In order to understand whether the

\footnotetext{
${ }^{17}$ Results from a specification with non nest-specific month fixed effects, available upon request, are qualitatively similar.
} 
Table 4: Readers' Demand

\begin{tabular}{|c|c|c|c|c|}
\hline VARIABLES & $\begin{array}{c}\text { (1) } \\
\text { Single- } \\
\text { Homing }\end{array}$ & $\begin{array}{c}(2) \\
\text { Single- } \\
\text { Homing }\end{array}$ & $\begin{array}{c}(3) \\
\text { Double- } \\
\text { Homing }\end{array}$ & $\begin{array}{c}(4) \\
\text { Double- } \\
\text { Homing }\end{array}$ \\
\hline Real cover price & $\begin{array}{c}-1.301 * * * \\
(-4.293)\end{array}$ & $\begin{array}{c}-1.199 * * * \\
(-3.918)\end{array}$ & $\begin{array}{c}-1.326 * * * \\
(-11.233)\end{array}$ & $\begin{array}{c}-1.120^{* * * *} \\
(-10.242)\end{array}$ \\
\hline$\sigma$ & $\begin{array}{c}0.177 * * * \\
(3.087)\end{array}$ & $\begin{array}{c}0.218 * * * \\
(3.921)\end{array}$ & $\begin{array}{c}0.736^{* * *} \\
(12.896)\end{array}$ & $\begin{array}{c}0.729 * * * \\
(13.117)\end{array}$ \\
\hline Advertising intensity (slots/pages) & $\begin{array}{c}0.005 * * * \\
(2.645)\end{array}$ & & $\begin{array}{c}-0.002 \\
(-1.334)\end{array}$ & \\
\hline Adv. intensity (slots/pages) - Generalist & & $\begin{array}{c}-0.002 \\
(-0.632)\end{array}$ & & $\begin{array}{c}-0.001 \\
(-0.942)\end{array}$ \\
\hline Adv. intensity (slots/pages) - Sport & & $\begin{array}{c}0.012 * * * \\
(6.459)\end{array}$ & & $\begin{array}{c}0.009 * * * \\
(10.445)\end{array}$ \\
\hline Adv. intensity (slots/pages) - Business & & $\begin{array}{l}0.012^{*} \\
(1.829)\end{array}$ & & $\begin{array}{c}-0.003 \\
(-0.883)\end{array}$ \\
\hline Generalist magazine (day) & $\begin{array}{c}0.323 * * * \\
(5.061)\end{array}$ & $\begin{array}{c}0.304 * * * \\
(4.769)\end{array}$ & $\begin{array}{c}0.298 * * * \\
(11.696)\end{array}$ & $\begin{array}{c}0.249 * * * \\
(10.616)\end{array}$ \\
\hline Generalist magazine plus (day) & & & $\begin{array}{c}0.246^{* * * *} \\
(5.332)\end{array}$ & $\begin{array}{c}0.205^{* * *} \\
(4.942)\end{array}$ \\
\hline Women magazine (day) & $\begin{array}{c}0.456 * * * \\
(4.365)\end{array}$ & $\begin{array}{c}0.429 * * * \\
(4.070)\end{array}$ & $\begin{array}{c}0.456^{* * *} \\
(11.715)\end{array}$ & $\begin{array}{c}0.384 * * * \\
(10.603)\end{array}$ \\
\hline Women magazine plus (day) & & & $\begin{array}{c}0.411 * * * \\
(11.762)\end{array}$ & $\begin{array}{c}0.355^{* * * *} \\
(11.078)\end{array}$ \\
\hline Economic insert (day) & $\begin{array}{c}-0.051 * * * \\
(-3.218)\end{array}$ & $\begin{array}{c}-0.045 * * * \\
(-2.953)\end{array}$ & $\begin{array}{l}-0.015^{*} \\
(-1.752)\end{array}$ & $\begin{array}{c}-0.005 \\
(-0.613)\end{array}$ \\
\hline Economic insert plus (day) & & & $\begin{array}{c}-0.036 * * * \\
(-3.117)\end{array}$ & $\begin{array}{c}-0.030 * * * \\
(-2.686)\end{array}$ \\
\hline Local pages & $\begin{array}{c}-0.003 \\
(-0.927)\end{array}$ & $\begin{array}{c}-0.003 \\
(-0.889)\end{array}$ & $\begin{array}{c}-0.002 \\
(-1.598)\end{array}$ & $\begin{array}{l}-0.001 \\
(-0.693)\end{array}$ \\
\hline Observations & 8,795 & 8,795 & 35,105 & 35,105 \\
\hline R-squared & 0.464 & 0.470 & 0.716 & 0.753 \\
\hline Number of Newspaper/Bundle - Weekday FE & 49 & 49 & 196 & 196 \\
\hline Website opening & YES & YES & YES & YES \\
\hline Editor dummy variables & YES & YES & YES & YES \\
\hline Newspaper/Bundle - Weekday Fixed Effects & YES & YES & YES & YES \\
\hline Time trend & $\begin{array}{l}\text { Year/Nest } \\
\text { Fixed Effects }\end{array}$ & $\begin{array}{l}\text { Year/Nest } \\
\text { Fixed Effects }\end{array}$ & $\begin{array}{l}\text { Year/Nest } \\
\text { Fixed Effects }\end{array}$ & $\begin{array}{c}\text { Year/Nest } \\
\text { Fixed Effects }\end{array}$ \\
\hline Seasonality & $\begin{array}{l}\text { Month/Nest } \\
\text { Fixed Effects }\end{array}$ & $\begin{array}{l}\text { Month/Nest } \\
\text { Fixed Effects }\end{array}$ & $\begin{array}{l}\text { Month/Nest } \\
\text { Fixed Effects }\end{array}$ & $\begin{array}{l}\text { Month/Nest } \\
\text { Fixed Effects }\end{array}$ \\
\hline Adjusted R-squared & 0.453 & 0.460 & 0.713 & 0.750 \\
\hline Kleibergen Paap stat. & 57.13 & 49.77 & 279 & 217.8 \\
\hline $\mathrm{p}$-value KP & $1.72 \mathrm{e}-10$ & $4.52 \mathrm{e}-08$ & 0 & 0 \\
\hline
\end{tabular}

Robust z-statistics in parentheses, ${ }^{* * *} \mathrm{p}<0.01,{ }^{* *} \mathrm{p}<0.05, * \mathrm{p}<0.1$.

indirect network externality is heterogeneous across newspaper types, in column (2) we allow for different advertising intensity effects by newspaper type. ${ }^{18}$ Interestingly, we find that the effect is negative but insignificant for general interest newspapers, while it is positive for sports and (albeit significant only at 10\%) business papers. This result is in line with previous findings: Argentesi and Filistrucchi (2007) find

\footnotetext{
${ }^{18} \mathrm{We}$ assume linear indirect network effects. See Sokullu (2016) for a model that allows for non-linear effects.
} 
insignificant effects of advertising quantity on readers demand with similar data on generalist newspapers. The positive effect for specialized papers (such as sports and business) may be due to the fact that advertising in these types of newspapers is also more specialized and targeted, thus being more valuable to readers. This is also consistent with previous findings: both Kaiser and Wright (2006) for specialized magazines and Song (2021) for TV magazines find that readers display an ad-loving attitude.

The estimated $\sigma$ is positive and statistically significant at the $1 \%$ significance level, thus showing that the chosen nesting structure matters.

The other coefficients have the expected signs and are mostly consistent with Argentesi and Filistrucchi (2007): both the coefficients for the dummy variables for the day of issue of a magazine of general information or the day of issue of a women magazine are positive and statistically significant at the $1 \%$ level. The coefficient for the dummy variable for the day of issue of an economic insert instead has a negative effect. The number of local pages in a newspaper does not significantly impact readers' demand. For the website dummy variables interacted with internet penetration rate, which account for the launch of a website by a given newspaper, the coefficients are jointly insignificant. We also include a set of editor dummy variables in the estimation. Standard errors are heteroskedasticity robust and corrected for autocorrelation of order 1. The Kleibergen-Paap test statistic for weak instruments indicates that there is no problem of weak instruments in the first stages.

Columns (3) and (4) of Table 4 show the estimation results for readers' demand accounting for double-homing by readers. The structure of the nests is richer than in the single-homing specification. Since demand is now modelled as demand for bundles of one or two newspapers, in addition to the outside good, there are now not only the nests of generalist, of sport, and of financial newspapers, but also the nests of generalists and sport, of generalist and financial, and of sport and financial bundles. See Figure 3 in Appendix A.3 for a description of the structure of the nests.

The estimated price coefficient is negative and significant at the $1 \%$ significance level in both specifications (3) and (4). The magnitude of the price coefficient is slightly larger than in the estimations under the assumption of single-homing by readers. Note that estimated coefficients are not directly comparable and do not allow for conclusions regarding which coefficients drive differences in elasticities as the single-homing model is estimated at the newspaper level while the double-homing model is estimated at the bundle level. The meaningful comparison is in terms of price elasticities, as we discuss below. Computing the marginal effects at the newspaper level suggests that a cover price increase of 10 cents decreases circulation on average between $58 \mathrm{~K}$ and $298 \mathrm{~K}$ readers depending on the newspaper. The advertising intensity coefficient is insignificant in specification (3). However, when allowing for different effects by newspaper type (column (4)), it appears that the effect is positive for sports newspapers, similar to the single-homing case (although it becomes insignificant for the business paper). The estimated $\sigma$ is again positive and significant at the $1 \%$ significance level and much larger than the nesting parameter in the estimations under the assumption of single-homing by readers. This is due to the fact that, when we account for double-homing, there are more and closer options/bundles to switch to within a nest.

The other coefficients have the expected signs: both the coefficients for the dummy variables for the day of issue of a magazine of general information or the day of issue of a women magazine are positive and statistically significant. Again, the coefficient of the dummy variable for the issue of an economic insert is negative but barely insignificant. The dummy variables for the day of issue of a 
specific magazine or insert now measure whether there is at least one of these magazines/inserts in the bundle on a particular day. Those variables marked "plus" measure in addition whether there was a magazine/women magazine/economic insert issued on the same day in both of the newspapers in the respective bundle. The effect of a second magazine or women's magazine in the bundle is positive and significant while the effect of a second economic insert is negative and significant. The number of local pages in the bundle does not have any significant impact on readers' demand for the bundle. In these specifications, most of the coefficients for website introduction are negative and jointly significant. Thus, introducing websites seems to negatively impact demand for printed newspapers, as in Filistrucchi (2005). The Kleibergen-Paap test statistic for weak instruments indicates that weak instruments are not a problem in the first stages.

\subsubsection{Elasticities}

Table 5 shows the resulting mean own- and cross-price elasticities for the seven newspapers based on the estimation results of the first column of Table 4, i.e., under the assumption of single-homing readers. While the mean own-price elasticity varies between -1.26 and -1.47 , the cross-price elasticities are small and vary between 0.008 and 0.16 .

While the dataset allowing for double-homing is at the bundle level, the price and network effect elasticities should still be at the product, i.e. newspaper, level. Thus, we sum over all relevant marginal effects at the bundle level to obtain the marginal effects at the newspaper level when we account for double-homing by readers. ${ }^{19}$ We then multiply these marginal effects with the respective price or advertising intensity (own or cross) and divide by the newspaper's market share to obtain the elasticities at the product level. $^{20}$

Table 6 shows the resulting mean own- and cross-price elasticities for the seven newspapers based on the estimation results of the third column in Table 4, i.e. under the assumption of double-homing readers. Firstly, the mean own-price elasticities now vary between -1.28 and -3.95 , which are much larger than the estimated mean own-price elasticities based on the assumption of single-homing readers. This is an intuitive result, since multi-homing readers can react to a price increase of a newspaper $A$ in their bundle of newspapers $\mathrm{AB}$ by switching to a close bundle containing B but not A. Thus, they may be more pricesensitive than single-homing readers, whose only alternative in case of a price change by a newspaper is switching to a completely different newspaper.

Secondly, note that cross-price elasticities can now be positive or negative. In particular, we find that cross-price elasticities between newspapers of the same type (i.e. generalist, sport, financial) are positive, while cross-price elasticities between newspapers of different types are negative. This implies that newspapers of the same newspaper type are substitutes while newspapers of different types are com-

\footnotetext{
${ }^{19}$ For example, for the own-price effect of newspaper A, we take into account the effects of a price increase of all bundles containing newspaper A on all bundles containing newspaper A. For, e.g., the cross-price effect on newspaper A of a price increase of newspaper B, we take into account the effect of a price increase of all bundles containing newspaper B on all bundles containing newspaper A. Note that this also includes the own-price effect of bundle AB increasing its price, which is negative.

${ }^{20}$ We multiply here with the market share based on the actual circulation of the newspaper contained in the newspaper level data. However, as a robustness check, we also computed the elasticities based on the newspaper market shares that are implied by the estimated newspaper circulation resulting from the procedure to create the bundle-level dataset. Qualitative results did not change when we used these alternative market shares in the computation of elasticities.
} 
Table 5: Mean Own- and Cross-Price Elasticities - Readers' Demand - Single-Homing

\begin{tabular}{|c|c|c|c|c|c|c|c|}
\hline & Corriere & $\begin{array}{c}\text { Corriere } \\
\text { Sport }\end{array}$ & $\begin{array}{c}\text { Gazzetta } \\
\text { Sport }\end{array}$ & Giornale & Repubblica & Il Sole & Stampa \\
\hline Corriere & $\begin{array}{c}-1.470 * * * \\
(0.306)\end{array}$ & $\begin{array}{c}0.010 * * * \\
(0.002)\end{array}$ & $\begin{array}{c}0.014 * * * \\
(0.003)\end{array}$ & $\begin{array}{c}0.042 * * \\
(0.016)\end{array}$ & $\begin{array}{c}0.111 * * \\
(0.043)\end{array}$ & $\begin{array}{c}0.012 * * * \\
(0.002)\end{array}$ & $\begin{array}{c}0.070 * * \\
(0.027)\end{array}$ \\
\hline Corriere Sport & $\begin{array}{c}0.023 * * * \\
(0.004)\end{array}$ & $\begin{array}{c}-1.305^{* * * *} \\
(0.268)\end{array}$ & $\begin{array}{c}0.159 * * \\
(0.067)\end{array}$ & $\begin{array}{c}0.008 * * * \\
(0.001)\end{array}$ & $\begin{array}{c}0.021 * * * \\
(0.004)\end{array}$ & $\begin{array}{c}0.012 * * * \\
(0.002)\end{array}$ & $\begin{array}{c}0.013 * * * \\
(0.002)\end{array}$ \\
\hline Gazzetta Sport & $\begin{array}{c}0.023 * * * \\
(0.004)\end{array}$ & $\begin{array}{c}0.117 * * \\
(0.049)\end{array}$ & $\begin{array}{c}-1.258 * * * \\
(0.253)\end{array}$ & $\begin{array}{c}0.008 * * * \\
(0.001)\end{array}$ & $\begin{array}{c}0.021 * * * \\
(0.004)\end{array}$ & $\begin{array}{c}0.012 * * * \\
(0.002)\end{array}$ & $\begin{array}{c}0.013 * * * \\
(0.002)\end{array}$ \\
\hline Giornale & $\begin{array}{c}0.122 * * \\
(0.047)\end{array}$ & $\begin{array}{c}0.010 * * * \\
(0.002)\end{array}$ & $\begin{array}{c}0.014 * * * \\
(0.003)\end{array}$ & $\begin{array}{c}-1.455^{* * *} \\
(0.312)\end{array}$ & $\begin{array}{c}0.111 * * \\
(0.043)\end{array}$ & $\begin{array}{c}0.012 * * * \\
(0.002)\end{array}$ & $\begin{array}{c}0.070 * * \\
(0.027)\end{array}$ \\
\hline Repubblica & $\begin{array}{c}0.121 * * \\
(0.047)\end{array}$ & $\begin{array}{c}0.010 * * * \\
(0.002)\end{array}$ & $\begin{array}{c}0.014 * * * \\
(0.003)\end{array}$ & $\begin{array}{c}0.042 * * \\
(0.016)\end{array}$ & $\begin{array}{c}-1.469 * * * \\
(0.307)\end{array}$ & $\begin{array}{c}0.012 * * * \\
(0.002)\end{array}$ & $\begin{array}{c}0.069 * * \\
(0.027)\end{array}$ \\
\hline Il Sole & $\begin{array}{c}0.023 * * * \\
(0.004)\end{array}$ & $\begin{array}{c}0.010 * * * \\
(0.002)\end{array}$ & $\begin{array}{c}0.014 * * * \\
(0.003)\end{array}$ & $\begin{array}{c}0.008 * * * \\
(0.001)\end{array}$ & $\begin{array}{c}0.021 * * * \\
(0.004)\end{array}$ & $\begin{array}{c}-1.306^{* * *} \\
(0.247)\end{array}$ & $\begin{array}{c}0.013 * * * \\
(0.002)\end{array}$ \\
\hline Stampa & $\begin{array}{c}0.122 * * \\
(0.047)\end{array}$ & $\begin{array}{c}0.010 * * * \\
(0.002)\end{array}$ & $\begin{array}{c}0.014 * * * \\
(0.003)\end{array}$ & $\begin{array}{c}0.042 * * \\
(0.016)\end{array}$ & $\begin{array}{c}0.111 * * \\
(0.043)\end{array}$ & $\begin{array}{c}0.012 * * * \\
(0.002)\end{array}$ & $\begin{array}{c}-1.437 * * * \\
(0.305)\end{array}$ \\
\hline
\end{tabular}

We report the mean elasticities over the years 1992-2006. Bootstrapped standard errors based on 5k bootstrapped samples are reported in parentheses. Cells report the quantity change of the newspaper in the row following a price change of the newspaper in the column.

Table 6: Mean Own- and Cross-Price Elasticities - Readers' Demand - Double-Homing

\begin{tabular}{|c|c|c|c|c|c|c|c|}
\hline & Corriere & $\begin{array}{c}\text { Corriere } \\
\text { Sport }\end{array}$ & $\begin{array}{c}\text { Gazzetta } \\
\text { Sport }\end{array}$ & Giornale & Repubblica & Il Sole & Stampa \\
\hline Corriere & $\begin{array}{c}-3.479 * * * \\
(0.722)\end{array}$ & $\begin{array}{l}-0.006 \\
(0.011)\end{array}$ & $\begin{array}{c}-0.141 * * * \\
(0.017)\end{array}$ & $\begin{array}{c}0.132 * * \\
(0.066)\end{array}$ & $\begin{array}{c}0.662 * * * \\
(0.256)\end{array}$ & $\begin{array}{c}-0.144 * * * \\
(0.014)\end{array}$ & $\begin{array}{c}0.645^{* * *} * \\
(0.213)\end{array}$ \\
\hline Corriere Sport & $\begin{array}{l}-0.017 \\
(0.026)\end{array}$ & $\begin{array}{c}-2.927 * * * \\
(0.590)\end{array}$ & $\begin{array}{c}1.165 * * * \\
(0.431)\end{array}$ & $\begin{array}{c}-0.063 * * * \\
(0.007)\end{array}$ & $\begin{array}{c}-0.233 * * * \\
(0.035)\end{array}$ & $\begin{array}{c}-0.064 * * * \\
(0.006)\end{array}$ & $\begin{array}{l}-0.009 \\
(0.007)\end{array}$ \\
\hline Gazzetta Sport & $\begin{array}{c}-0.235 * * * \\
(0.029)\end{array}$ & $\begin{array}{c}0.857 * * * \\
(0.317)\end{array}$ & $\begin{array}{c}-2.416 * * * \\
(0.416)\end{array}$ & $\begin{array}{c}-0.033 * * * \\
(0.005)\end{array}$ & $\begin{array}{c}-0.023 \\
(0.021)\end{array}$ & $\begin{array}{c}-0.068 * * * \\
(0.007)\end{array}$ & $\begin{array}{c}-0.066 * * * \\
(0.008)\end{array}$ \\
\hline Giornale & $\begin{array}{c}0.382 * * \\
(0.192)\end{array}$ & $\begin{array}{c}-0.080 * * * \\
(0.010)\end{array}$ & $\begin{array}{c}-0.054 * * * \\
(0.008)\end{array}$ & $\begin{array}{c}-3.951 * * * \\
(0.903)\end{array}$ & $\begin{array}{c}0.766^{* * * *} \\
(0.275)\end{array}$ & $\begin{array}{c}-0.150 * * * \\
(0.015)\end{array}$ & $\begin{array}{c}0.471 * * * \\
(0.168)\end{array}$ \\
\hline Repubblica & $\begin{array}{c}0.723 * * * \\
(0.280)\end{array}$ & $\begin{array}{c}-0.109 * * * \\
(0.016)\end{array}$ & $\begin{array}{l}-0.017 \\
(0.013)\end{array}$ & $\begin{array}{c}0.294 * * * \\
(0.105)\end{array}$ & $\begin{array}{c}-3.629 * * * \\
(0.760)\end{array}$ & $\begin{array}{c}-0.140 * * * \\
(0.014)\end{array}$ & $\begin{array}{c}0.614 * * * \\
(0.208)\end{array}$ \\
\hline Il Sole & $\begin{array}{c}-0.266 * * * \\
(0.026)\end{array}$ & $\begin{array}{c}-0.051 * * * \\
(0.005)\end{array}$ & $\begin{array}{c}-0.075 * * * \\
(0.007)\end{array}$ & $\begin{array}{c}-0.095 * * * \\
(0.009)\end{array}$ & $\begin{array}{c}-0.237 * * * \\
(0.023)\end{array}$ & $\begin{array}{c}-1.276 * * * \\
(0.124)\end{array}$ & $\begin{array}{c}-0.098 * * * \\
(0.010)\end{array}$ \\
\hline Stampa & $\begin{array}{c}1.126 * * * \\
(0.372)\end{array}$ & $\begin{array}{l}-0.007 \\
(0.005)\end{array}$ & $\begin{array}{c}-0.071 * * * \\
(0.008)\end{array}$ & $\begin{array}{c}0.282 * * * \\
(0.101)\end{array}$ & $\begin{array}{c}0.984 * * * \\
(0.333)\end{array}$ & $\begin{array}{c}-0.093 * * * \\
(0.009)\end{array}$ & $\begin{array}{c}-3.796 * * * \\
(0.836)\end{array}$ \\
\hline
\end{tabular}

We report the mean elasticities over the years 1992-2006. Bootstrapped standard errors based on 5k bootstrapped samples are reported in parentheses. Cells report the quantity change of the newspaper in the row following a price change of the newspaper in the column. 


\begin{tabular}{lc}
\hline & $(1)$ \\
VARIABLES & \\
\hline Log(advertising price index $)$ & $-1.727 * * *$ \\
& $(-3.744)$ \\
$\log (\mathrm{GDP})$ & $12.173^{* * *}$ \\
& $(11.063)$ \\
Constant & $470.552^{* * *}$ \\
& $(5.703)$ \\
& \\
Observations & 1,260 \\
Time trend & Weekday specific quadratic yearly trend \\
Seasonality & Month Fixed Effects \\
Kleibergen Paap stat. & 22.05 \\
p-value KP & $6.37 \mathrm{e}-05$ \\
\multicolumn{2}{c}{ Robust z-statistics in parentheses, $* * * \mathrm{p}<0.01, * * \mathrm{p}<0.05, * \mathrm{p}<0.1$}
\end{tabular}

plements. ${ }^{21}$ Additionally, the magnitude of the cross-price elasticities is mostly larger than those based on the assumption of single-homing by readers. Some of the cross-price elasticities are insignificant, indicating that the newspapers are independent goods. This is the case for the generalist/sports pairs Corriere della Sera/Corriere dello Sport, La Stampa/Corriere dello Sport, and La Repubblica/Gazzetta dello Sport.

\subsection{Advertisers' Demand}

\subsubsection{Estimation Results}

Here, we present the results on the estimation of advertisers' demand, first at the top level, where advertisers decide on the budget to spend on advertising in print newspapers and, second, at the newspaper level, where advertisers decide on how to split this advertising budget across the different newspapers. Since we aim to highlight the possible bias due to the omission of information on multi-homing by readers, we present results from two specifications disregarding information on double-homing by readers; the other two making use of the information on captive readers and overlapping readers between newspapers.

Table 7 shows results for top level advertisers' demand. The coefficient on the price index is negative and statistically significant at the $1 \%$ significance level, implying an overall price elasticity of advertising demand in these seven newspapers of 1.7. Thus, aggregate advertising demand seems to be very elastic, suggesting that printed daily papers are subject to a relevant competitive constraint from other media. GDP, as an indicator for the overall business cycle, has a positive and statistically significant effect on overall advertising demand. We account for the time trend by including a weekday-specific quadratic yearly time trend and allow for seasonality by including month fixed effects.

Table 8 shows the estimation results for advertisers' demand at the newspaper level. Specifications (1) and (2) show estimation results when information on single-homing and multi-homing readers is omitted. Both specifications contain newspaper and weekday fixed effects as well as a newspaper type-

\footnotetext{
${ }^{21}$ We also estimated a nested logit model allowing for different $\sigma$ s for each nest. We still find that newspapers of the same type are substitutes while newspapers of different types are complements.
} 
specific (generalist, sport, business) quadratic yearly time trend. Seasonality is accounted for by month fixed effects. The two specifications differ in the way we model $d_{j}$, the coefficient on $\ln \left(\frac{x_{t d}}{P_{t d}}\right)$ that links the top level with the newspaper level advertising demand. While in specification (1) $\ln \left(\frac{x_{t d}}{P_{t d}}\right)$ is interacted with newspaper dummy variables, we model $d_{j}$ as a function of newspaper circulation in specification (2).

Specifications (3) and (4) in Table 8 instead show estimation results for advertisers' demand at the newspaper level when information on the percentage of captive readers and the percentage of overlapping readers is used. As before, the specifications differ in the way we model $d_{j}$, i.e., whether $d_{j}$ is just a newspaper specific coefficient (specification 3 ) or whether $d_{j}$ is modeled as a function of newspaper characteristics (specification 4).

Consider first specifications (1) and (3). The coefficient on advertising price is negative and significant at the $1 \%$ significance level in specification (1). The interaction term between the advertising slot price and the percentage of female readers is positive and significant. This implies that advertisers' demand is less elastic for newspapers that offer access to more female readers.

In specification (3), we additionally allow the own advertising price elasticity to depend on the percentage of captive readers of the newspaper. The coefficient on advertising price is negative and significant at the $1 \%$ level and much larger in magnitude than in specification (1), when information on multi-homing by readers is ignored in the estimation of advertising demand. Indeed, when we do not use information on double-homing by readers on the advertiser side, we implicitly assume that readers single-home. If advertisers can reach readers via only one newspaper, they should be less price-sensitive than in the case where they can reach the same reader in more than one newspaper. The interaction term between the advertising slot price and the percentage of female readers is not just still positive and significant, but also larger in magnitude than in specification (1). Importantly, the interaction term between the advertising slot price and the percentage of captive readers is also positive and significant, which implies that advertisers' demand is less elastic for newspapers that offer exclusive access to more captive readers. Consistent with theoretical models, advertisers attach a greater value to exclusive readers. Finally, the interaction term between price, the percentage of captive readers, and the percentage of female readers is negative and significant. This might be due to the fact that captive men are more valuable because they are scarcer than captive women, although we do not have this type of information in our data.

The coefficient on the own circulation is positive and significant at the $1 \%$ significance level in both specifications, highlighting that advertisers value a newspaper more, the more readers this newspaper reaches (all else equal).

Cross-price effects are modeled as a function of the closeness in the income of newspaper readers and, in specification (3) when we take into account multi-homing reader information, also as a function of the overlap in readers between two newspapers. The reader income based cross-price measure is positive and significant in specification (1), implying that higher prices of competing newspapers increase own advertising demand and that newspapers are closer substitutes for advertisers if they reach readers that are similar/close in terms of socio-economic status/income. Advertisers respond to a newspaper's price increase by placing ads in an outlet with a similar target audience, thereby minimizing the probability of reaching the same readers twice. This is consistent with the fact that there are diminishing returns 
Table 8: Advertisers' Demand - Newspaper Level

\begin{tabular}{|c|c|c|c|c|}
\hline VARIABLES & $\begin{array}{c}(1) \\
\text { No Info on } \\
\text { DH } \\
\text { Readers }\end{array}$ & $\begin{array}{c}(2) \\
\text { No Info on } \\
\text { DH } \\
\text { Readers }\end{array}$ & $\begin{array}{c}\text { (3) } \\
\text { With Info } \\
\text { on DH } \\
\text { Readers }\end{array}$ & $\begin{array}{c}\text { (4) } \\
\text { With Info } \\
\text { on DH } \\
\text { Readers }\end{array}$ \\
\hline $\log ($ real price per ad slot $)$ & $\begin{array}{c}-0.084 * * * \\
(-5.697)\end{array}$ & $\begin{array}{c}-0.128 * * * \\
(-4.999)\end{array}$ & $\begin{array}{c}-0.446 * * * \\
(-6.077)\end{array}$ & $\begin{array}{c}-0.498 * * * \\
(-8.602)\end{array}$ \\
\hline $\log ($ real price per ad slot)* $\log$ (captive readers) & & & $\begin{array}{c}0.097 * * * \\
(5.099)\end{array}$ & $\begin{array}{l}0.137 * * * \\
(9.725)\end{array}$ \\
\hline $\log ($ real price per ad slot $) * \log ($ female readers $)$ & $\begin{array}{l}0.020 * * * \\
(7.049)\end{array}$ & $\begin{array}{l}0.012 * * * \\
(3.805)\end{array}$ & $\begin{array}{l}0.154 * * * \\
(7.540)\end{array}$ & $\begin{array}{l}0.153 * * * \\
(9.998)\end{array}$ \\
\hline $\begin{array}{l}\log (\text { real price per ad slot }) * \log (\text { captive readers }) \\
\text { *Log(female readers })\end{array}$ & & & $\begin{array}{c}-0.034 * * * \\
(-6.211)\end{array}$ & $\begin{array}{l}-0.042^{* * *} \\
(-10.427)\end{array}$ \\
\hline $\log ($ circulation $)$ & $\begin{array}{l}0.258 * * * \\
(15.232)\end{array}$ & $\begin{array}{l}0.424 * * * \\
(14.923)\end{array}$ & $\begin{array}{l}0.283 * * * \\
(17.305)\end{array}$ & $\begin{array}{l}0.295 * * * \\
(17.944)\end{array}$ \\
\hline Readers' income cross-price measure & $\begin{array}{l}0.014 * * * \\
(6.540)\end{array}$ & $\begin{array}{l}0.020 * * * \\
(6.276)\end{array}$ & $\begin{array}{c}0.003 \\
(1.412)\end{array}$ & $\begin{array}{c}0.017 * * * \\
(9.028)\end{array}$ \\
\hline Joint readers cross-price measure & & & $\begin{array}{c}0.020 * * * \\
(2.694)\end{array}$ & $\begin{array}{c}0.031 * * * \\
(5.363)\end{array}$ \\
\hline Same type cross-circulation measure & $\begin{array}{c}-0.006^{* * *} * \\
(-11.071)\end{array}$ & $\begin{array}{c}-0.003 * * * \\
(-4.444)\end{array}$ & $\begin{array}{c}-0.006^{* * *} * \\
(-8.854)\end{array}$ & $\begin{array}{c}-0.005 * * * \\
(-7.619)\end{array}$ \\
\hline $\log (\mathrm{xt} / \mathrm{Pt}) *$ Corriere & $\begin{array}{c}0.016 \\
(0.878)\end{array}$ & & $\begin{array}{c}-0.073 * * * \\
(-3.924)\end{array}$ & \\
\hline $\log (\mathrm{xt} / \mathrm{Pt}) *$ Corriere Sport & $\begin{array}{c}0.256 * * * \\
(14.033)\end{array}$ & & $\begin{array}{c}0.169 * * * \\
(11.127)\end{array}$ & \\
\hline $\log (\mathrm{xt} / \mathrm{Pt}) *$ Gazzetta Sport & $\begin{array}{c}0.254 * * * \\
(13.971)\end{array}$ & & $\begin{array}{c}0.196 * * * \\
(11.553)\end{array}$ & \\
\hline $\log (\mathrm{xt} / \mathrm{Pt}) *$ Giornale & $\begin{array}{c}0.121 * * * \\
(5.931)\end{array}$ & & $\begin{array}{c}0.159 * * * \\
(7.985)\end{array}$ & \\
\hline $\log (\mathrm{xt} / \mathrm{Pt}) *$ Repubblica & $\begin{array}{l}0.030 * \\
(1.707)\end{array}$ & & $\begin{array}{c}-0.083 * * * \\
(-4.738)\end{array}$ & \\
\hline $\log (x t / P t) *$ Il Sole & $\begin{array}{c}0.294 * * * \\
(14.726)\end{array}$ & & $\begin{array}{c}0.209 * * * \\
(11.299)\end{array}$ & \\
\hline $\log (x t / P t) *$ Stampa & $\begin{array}{c}0.297 * * * \\
(16.440)\end{array}$ & & $\begin{array}{c}0.123 * * * \\
(7.105)\end{array}$ & \\
\hline $\log (\mathrm{xt} / \mathrm{Pt}) * \operatorname{Diff}($ circulation) (Mio.) & & $\begin{array}{c}-0.117 * * * \\
(-4.997)\end{array}$ & & \\
\hline $\log (\mathrm{xt} / \mathrm{Pt}) * \operatorname{Diff}($ circulation*captive readers) (Mio.) & & & & $\begin{array}{c}-0.002 * * * \\
(-5.647)\end{array}$ \\
\hline Observations & 8,795 & 8,795 & 8,795 & 8,795 \\
\hline Number of id & 7 & 7 & 7 & 7 \\
\hline Newspaper Fixed Effects & YES & YES & YES & YES \\
\hline Weekday Fixed Effects & YES & YES & YES & YES \\
\hline Type specific quadratic yearly trend & YES & YES & YES & YES \\
\hline Month Fixed Effects & YES & YES & YES & YES \\
\hline Kleibergen Paap stat. & 416.8 & 230.3 & 482.3 & 470.3 \\
\hline p-value KP & 0 & 0 & 0 & 0 \\
\hline Chi-squared $\sum_{j=1}^{J} d_{j}=0$ & 135.9 & & 51.02 & \\
\hline $\mathrm{p}$-value & 0 & & 0 & \\
\hline
\end{tabular}


to advertising, ${ }^{22}$ and it is even more evident when we include information on readers multi-homing in the estimation. The coefficient on the joint readers cross-price measure in specification (3) is positive and significant, showing that newspapers are closer substitutes for advertisers if they have a higher share of readers in common; i.e., if these readers can be reached via either of the two newspapers. The coefficient is also much larger in magnitude than that for the reader income based cross-price measure in specification (1), thus the overlap in readers seems to be a more important determinant of substitutability of newspapers for advertisers than readers' income. In particular, the reader income based cross-price measure is no longer significant in specification (3) where we allow cross-price effects to depend on the share of common readers. Indeed, if advertisers want to avoid reaching readers twice, the overlap in readers is certainly a more informative measure than their average income.

Cross-circulation effects are modeled as a function of the discrete closeness measure of newspaper type in both specifications. The negative and statistically significant coefficient on the same type crosscirculation measure shows that higher circulation of competing newspapers of the same newspaper type decreases own advertising demand.

Lastly, not all $\ln \left(\frac{x_{t d}}{P_{t d}}\right)$ terms are statistically significant in specifications (1) and (3), indicating that, for some newspapers, an increase in the overall print advertising budget does not affect their advertising sales share, while other newspapers gain or lose sales share with increasing overall print newspaper advertising expenditures. As discussed in Section 4, the theoretical model implies that $\sum_{j=1}^{J} d_{j}=0$ must hold. We do not impose this constraint ex ante, but estimate the unrestricted model and test whether the constraint holds ex post. The H0 hypothesis of all $d_{j}$ adding up to zero is clearly rejected both in specifications (1) and (3). This implies that advertiser demand might be misspecified and that the way of modelling the link between top level and newspaper level demand is crucial for correctly estimating advertising demand.

Thus, we go one step further by investigating which newspaper characteristics drive whether $d_{j}$ is negative or positive. Note that in specification (3), the $d_{j}$ is negative for Corriere della Sera and La Repubblica. These are the largest newspapers both in terms of circulation and advertising expenditure share. The negative $d_{j}$ implies that if total advertising expenditure $x_{t d}$ increases, the advertising sales share of these large newspapers decreases. Inversely, it implies that if total advertising expenditure $x_{t d}$ decreases, the advertising sales share of Corriere della Sera and La Repubblica increases. Thus, these two newspapers are kind of "must-have" newspapers for advertisers: If they decide to advertise in national print newspapers, then they first place ads in these two newspapers. Only if the overall advertising budget for print newspapers increases, ads will be placed also in other newspapers. Therefore, we model $d_{j}$ as a function of newspapers size, measured by circulation, in specification (2). As explained in section 4 , we use the difference between the newspaper circulation and the mean circulation across the seven newspapers, in order to ensure that the restriction of $\sum_{j=1}^{J} d_{j}=0$ holds by construction. Indeed, the coefficient on $\ln \left(\frac{x_{t d}}{P_{t d}}\right)$ interacted with the circulation measure is negative and statistically significant. This implies that if a newspaper has a circulation higher than the average circulation across newspapers, its advertising sales share decreases if total advertising expenditure $x_{t d}$ increases. Conversely, if a newspaper is small in the sense that its circulation is lower than the average circulation, its advertising sales share increases following an increase in total advertising expenditure $x_{t d}$.

\footnotetext{
${ }^{22}$ See for instance Athey, Calvano, and Gans (2018).
} 
Lastly, in specification (4), where reader multi-homing is taken into account, we take the idea of "must-have" newspapers one step further. Rather than making $d_{j}$ a function of circulation only, we use the information on single-homing readers and model $d_{j}$ as a function of captive circulation. Indeed, the estimated coefficient is negative and statistically significant, while all other estimated coefficients are in line with the results of specification (3). The intuition behind this negative effect is that a newspaper is a "must-have" newspaper for advertisers not only the higher its circulation but also the higher its number of captive readers. This evidence is consistent with the theoretical finding that, by placing ads in newspapers with a larger and more exclusive readership, advertisers avoid duplicating ad impressions (see Athey, Calvano, and Gans (2018)).

The other estimated coefficients are in line with the previous specifications.

\subsubsection{Elasticities}

As we have shown that taking into account information on single-homing and multi-homing readers is crucial for correctly estimating advertising demand, we present price elasticities as well as network effect elasticities based only on specification (4). Table 9 shows the resulting mean conditional own- and crossprice elasticities for advertising demand of the seven newspapers based on specification (4). The mean conditional own-price elasticity varies between -0.86 and -1.08 . The statistically significant conditional cross-price elasticities vary between 0.007 and 0.31 .

Table 9: Mean Conditional Own- and Cross-Price Elasticities - Advertisers' Demand - Including DH Readers

\begin{tabular}{lccccccc}
\hline & Corriere & $\begin{array}{c}\text { Corriere } \\
\text { Sport }\end{array}$ & $\begin{array}{c}\text { Gazzetta } \\
\text { Sport }\end{array}$ & Giornale & Repubblica & Il Sole & Stampa \\
\hline \multirow{2}{*}{ Corriere } & $-1.001^{* * *}$ & $0.010^{* * *}$ & $0.024^{* * *}$ & $0.016^{* * *}$ & $0.049 * * *$ & $0.029^{* * * *}$ & $0.019^{* * *}$ \\
& $(0.048)$ & $(0.001)$ & $(0.004)$ & $(0.002)$ & $(0.006)$ & $(0.004)$ & $(0.002)$ \\
Corriere Sport & -0.030 & $-0.979^{* *}$ & $0.310^{* * *}$ & $0.016^{* *}$ & 0.001 & -0.020 & -0.012 \\
& $(0.022)$ & $(0.425)$ & $(0.065)$ & $(0.007)$ & $(0.026)$ & $(0.013)$ & $(0.011)$ \\
Gazzetta Sport & $0.108^{* * *}$ & $0.113^{* * *}$ & $-0.863^{* * *}$ & $0.031^{* * *}$ & $0.079^{* * *}$ & $0.047^{* * *}$ & $0.056^{* * *}$ \\
& $(0.018)$ & $(0.020)$ & $(0.239)$ & $(0.005)$ & $(0.012)$ & $(0.007)$ & $(0.008)$ \\
Giornale & 0.000 & $0.020^{* * *}$ & $0.057^{* * *}$ & $-0.943^{* * *}$ & -0.030 & 0.016 & -0.020 \\
& $(0.031)$ & $(0.008)$ & $(0.018)$ & $(0.258)$ & $(0.024)$ & $(0.019)$ & $(0.012)$ \\
Repubblica & $0.055^{* * *}$ & $0.012^{* * *}$ & $0.019^{* * *}$ & $0.017^{* * *}$ & $-1.010^{* * *}$ & $0.032^{* * *}$ & $0.022^{* * *}$ \\
& $(0.006)$ & $(0.002)$ & $(0.003)$ & $(0.002)$ & $(0.052)$ & $(0.004)$ & $(0.003)$ \\
Il Sole & 0.007 & $0.007^{* * *}$ & $0.019^{* * *}$ & $0.016^{* * *}$ & 0.012 & $-0.990^{* * * *}$ & -0.001 \\
& $(0.012)$ & $(0.003)$ & $(0.006)$ & $(0.004)$ & $(0.011)$ & $(0.103)$ & $(0.005)$ \\
Stampa & $0.042^{* * *}$ & $0.013^{* * *}$ & $0.032^{* * *}$ & $0.015^{* * *}$ & $0.044^{* * *}$ & $0.030^{* * *}$ & $-1.082^{* * *}$ \\
& $(0.005)$ & $(0.002)$ & $(0.005)$ & $(0.002)$ & $(0.006)$ & $(0.004)$ & $(0.094)$ \\
\hline
\end{tabular}

We report the mean elasticities over the years 1992-2006. Bootstrapped standard errors based on 5k bootstrapped samples are reported in parentheses. Cells report the quantity change of the newspaper in the row following a price change of the newspaper in the column.

Looking at the formula for the conditional own-price elasticity in equation (11), note first that the $b_{j j}$ will increase, the higher the percentage of female readers and captive readers of newspaper $j$. This implies that newspapers with a high percentage of captive or a high percentage of female readers should 
have a smaller own-price elasticity, ceteris paribus. However, the interaction term between price, the percentage of captive readers, and the percentage of female readers is negative in specification (4). This implies that advertisers' demand is less elastic for newspapers that offer exclusive access to more captive readers, particularly if the latter are men. Secondly, note that a positive (negative) $d_{j}$ implies a higher (lower) conditional own-price elasticity (in absolute value) via its effect on the price index $P_{t d}$, which in turn has an effect on the expenditure share $w_{j t d}$. This implies that a newspaper for which the estimated $d_{j}$ is positive should have a larger conditional own-price elasticity than a newspaper with a negative estimate of $d_{j}$, ceteris paribus. Lastly, the conditional own-price elasticity also depends on the advertising sales share $w_{j t d}$. However, whether a high advertising sales share increases or decreases the conditional ownprice elasticity depends on the sign of the marginal effect of price on the sales share $w_{j t d}$, i.e., the sign of the $b_{j j}$. The average marginal effect of own price on the expenditure share $w_{j t d}$ is positive for all newspapers based on the results of specification (4), i.e., the quantity decreases by less than the price increases, implying inelastic demand. Secondly, given that the $b_{j j}$ is positive, a high advertising sales share $w_{j t d}$ actually increases the own-price elasticity (in absolute value), implying more elastic demand. The interaction between all of these effects determines the conditional own-price elasticity.

Corriere della Sera, La Repubblica, and La Stampa have the highest conditional own-price elasticities, while the two sport newspapers, Corriere dello Sport and Gazzetta dello Sport, have relatively lower conditional own-price elasticities (in absolute value) in Table 9. The relatively high own-price elasticities of Corriere della Sera and La Repubblica can be explained by their high advertising sales share $w_{j t d}(28 \%$ and $26 \%$, respectively, compared to a mean across newspapers of $14 \%$ ), while the high own-price elasticity of La Stampa is driven by its high share of both female and captive readers (42\% and $62 \%$ compared to means across newspapers of $32 \%$ and $43 \%$, respectively). While either a high share of female or a high share of captive readers lead to a low own-price elasticity, if both percentages are high, the negative interaction effect leading to more elastic demand, kicks in. The relatively low own-price elasticities of the two sport newspapers, on the other hand, can be explained by the relatively large positive average marginal effect driven by the relatively many single-homing male readers as well as the low advertising sales share (4\% and $6 \%$ compared to a mean across newspapers of $14 \%$ ), implying less elastic demand. ${ }^{23}$

The cross-price elasticities between two newspapers will be higher the more similar two newspapers are in terms of socio-economic status of their readers and the more joint readers two newspapers have, ceteris paribus (see the formula for the conditional cross-price elasticities in equation (11)). Secondly, note that a positive (negative) $d_{j}$ implies a lower (higher) conditional cross-price elasticity. Lastly, the conditional cross-price elasticities also depend on the advertising sales shares of newspapers $j$ and $k, w_{j t d}$ and $w_{k t d}$. The effects of $w_{j t d}$ and $w_{k t d}$ on the cross-price elasticity depend on the sign of the $d_{j}$. Thus, the interaction between all of these effects determines the conditional cross-price elasticities. Note, in particular, the relatively large cross-price elasticities between the two sport newspapers, Corriere dello Sport and Gazzetta dello Sport, in Table 9. Their cross-price elasticities are driven by the high share of readers that these two newspapers have in common (see Table 1) as well as their low advertising sales shares $w_{j t d}$.

Unconditional advertising price elasticities also need to take into account how advertising price increases by one newspaper change the overall price index for advertising in newspapers, how this in turn

\footnotetext{
${ }^{23}$ See Appendix A.6 for the relevant newspaper level summary statistics.
} 
Table 10: Mean Unconditional Own- and Cross-Price Elasticities - Advertisers' Demand - Including DH Readers

\begin{tabular}{|c|c|c|c|c|c|c|c|}
\hline & Corriere & $\begin{array}{c}\text { Corriere } \\
\text { Sport }\end{array}$ & $\begin{array}{c}\text { Gazzetta } \\
\text { Sport }\end{array}$ & Giornale & Repubblica & Il Sole & Stampa \\
\hline Corriere & $\begin{array}{c}-1.189 * * * \\
(0.049)\end{array}$ & $\begin{array}{c}-0.017 * * * \\
(0.001)\end{array}$ & $\begin{array}{c}-0.018 * * * \\
(0.004)\end{array}$ & $\begin{array}{c}-0.022 * * * \\
(0.002)\end{array}$ & $\begin{array}{c}-0.126^{* * * *} \\
(0.007)\end{array}$ & $\begin{array}{c}-0.079 * * * \\
(0.005)\end{array}$ & $\begin{array}{c}-0.076 * * * \\
(0.003)\end{array}$ \\
\hline Corriere Sport & $\begin{array}{c}-0.321 * * * \\
(0.030)\end{array}$ & $\begin{array}{c}-1.017 * * \\
(0.425)\end{array}$ & $\begin{array}{c}0.249 * * * \\
(0.064)\end{array}$ & $\begin{array}{c}-0.042 * * * \\
(0.008)\end{array}$ & $\begin{array}{c}-0.276^{* * *} * \\
(0.033)\end{array}$ & $\begin{array}{c}-0.190 * * * \\
(0.018)\end{array}$ & $\begin{array}{c}-0.159 * * * \\
(0.015)\end{array}$ \\
\hline Gazzetta Sport & $\begin{array}{c}-0.079 * * * \\
(0.018)\end{array}$ & $\begin{array}{c}0.087 * * * \\
(0.020)\end{array}$ & $\begin{array}{c}-0.904 * * * \\
(0.239)\end{array}$ & $\begin{array}{l}-0.006 \\
(0.005)\end{array}$ & $\begin{array}{c}-0.097 * * * \\
(0.013)\end{array}$ & $\begin{array}{c}-0.062 * * * \\
(0.008)\end{array}$ & $\begin{array}{c}-0.039 * * * \\
(0.008)\end{array}$ \\
\hline Giornale & $\begin{array}{c}-0.310 * * * \\
(0.040)\end{array}$ & $\begin{array}{c}-0.023 * * * \\
(0.008)\end{array}$ & $\begin{array}{l}-0.011 \\
(0.018)\end{array}$ & $\begin{array}{c}-1.002 * * * \\
(0.258)\end{array}$ & $\begin{array}{c}-0.318 * * * \\
(0.034)\end{array}$ & $\begin{array}{c}-0.160 * * * \\
(0.024)\end{array}$ & $\begin{array}{c}-0.175^{* * * *} \\
(0.018)\end{array}$ \\
\hline Repubblica & $\begin{array}{c}-0.128 * * * \\
(0.008)\end{array}$ & $\begin{array}{c}-0.013 * * * \\
(0.002)\end{array}$ & $\begin{array}{c}-0.020 * * * \\
(0.003)\end{array}$ & $\begin{array}{c}-0.020 * * * \\
(0.002)\end{array}$ & $\begin{array}{c}-1.183 * * * \\
(0.051)\end{array}$ & $\begin{array}{c}-0.076^{* * *} \\
(0.005)\end{array}$ & $\begin{array}{c}-0.071 * * * \\
(0.004)\end{array}$ \\
\hline Il Sole & $\begin{array}{c}-0.233 * * * \\
(0.015)\end{array}$ & $\begin{array}{c}-0.026^{* * *} \\
(0.003)\end{array}$ & $\begin{array}{c}-0.035 * * * \\
(0.006)\end{array}$ & $\begin{array}{c}-0.031 * * * \\
(0.005)\end{array}$ & $\begin{array}{c}-0.210 * * * \\
(0.014)\end{array}$ & $\begin{array}{c}-1.124 * * * \\
(0.103)\end{array}$ & $\begin{array}{c}-0.122 * * * \\
(0.007)\end{array}$ \\
\hline Stampa & $\begin{array}{c}-0.147 * * * \\
(0.006)\end{array}$ & $\begin{array}{c}-0.013 * * * \\
(0.002)\end{array}$ & $\begin{array}{c}-0.010 * \\
(0.005)\end{array}$ & $\begin{array}{c}-0.023 * * * \\
(0.002)\end{array}$ & $\begin{array}{c}-0.132 * * * \\
(0.007)\end{array}$ & $\begin{array}{c}-0.080 * * * \\
(0.005)\end{array}$ & $\begin{array}{c}-1.178 * * * \\
(0.094)\end{array}$ \\
\hline
\end{tabular}

We report the mean elasticities over the years 1992-2006. Bootstrapped standard errors based on 5k bootstrapped samples are reported in parentheses. Cells report the quantity change of the newspaper in the row following a price change of the newspaper in the column.

then changes the overall demand for advertising in print newspapers at the top level (relative to other media outlets), and how this change in total advertising expenditures $x_{t d}$ then affects the advertising quantity demanded on newspaper $j$ (budget effect). The unconditional price-elasticities for advertising demand take these effects into account and are given in Table 10 based on the estimation results of specification (4). Given that a price increase by one newspaper will result in a price increase in the price index $P_{t d}$, which subsequently leads to a decrease in the overall budget spend on advertising in national print newspapers at the top-level, we expect own-price elasticities to increase (in absolute value) and cross-price elasticities to decrease.

This is reflected in the unconditional price elasticities in Table 10. All own-price elasticities are higher in absolute value than the conditional ones and now vary between -0.9 and -1.19 . In particular, when taking the change in total advertising expenditures for newspapers into account, advertising demand for all newspapers, except Gazzetta dello Sport, is now elastic. All cross-price elasticities are lower than the conditional ones, to the point where most of the positive conditional cross-price elasticities turn into negative unconditional cross-price elasticities. In these cases, the positive substitution effect is dominated by the negative budget effect: a price increase by newspaper $k$ leads to an increase in the price index $P_{t d}$, which leads to a subsequent decrease in the overall budget spent (in real terms) on advertising in national print newspapers at the top-level, which in turn lowers the advertising quantity demanded on newspaper $j$. One exception are the unconditional cross-price elasticities between the two sport newspapers, Corriere dello Sport and Gazzetta dello Sport, which remain positive. Here, the positive substitution effect dominates the negative budget effect, for two reasons. Firstly, as noted before, the two newspapers have many readers in common and, therefore, are close substitutes. Secondly, both newspapers are small in terms of advertising sales share implying a small budget effect. The importance 
of newspaper size (in terms of advertising sales share) for the budget effect is also reflected in both the own- and cross-price elasticities of the two largest newspapers Corriere della Sera and La Repubblica. Given their size, a price increase by one of these newspapers leads to a large increase in the price index and, therefore, large decrease in total advertising expenditures $x_{t d}$ set at the top level. This large budget effect is reflected in the large changes between conditional and unconditional elasticities for these two newspapers (comparing columns 1 and 5 of Table 9 and Table 10).

Lastly, Table 11 shows the own- and cross-network effect elasticities based on the newspaper level advertising demand estimation results of specification (4). As the cross-circulation effects are modelled as a function of the discrete closeness measure of newspaper type, cross-circulation effects are zero by construction between newspapers of different newspaper types. Own-network effect elasticities vary between 1.12 and 9.52, while the cross-network effect elasticities are small and vary between -0.17 and -0.02. Note that the own-network effect elasticities are given by the coefficient on the own circulation divided by the advertising sales share $w_{j t}$ of newspaper $j$ (see equation (13)). This implies that newspapers with a low advertising sales share will have larger own-network effect elasticities, which is the case for Corriere dello Sport, Gazzetta dello Sport, and Il Giornale.

Table 11: Mean Own- and Cross-Circulation Elasticities - Advertisers' Demand - Including DH Readers

\begin{tabular}{lcccc}
\hline & $\begin{array}{c}\text { Own Circulation } \\
\text { Elasticity }\end{array}$ & General Interest & Sports & Business \\
\hline \multirow{2}{*}{ Corriere } & & $-0.020^{* * *}$ & 0 & 0 \\
& $1.108^{* * *}$ & $(0.002)$ & - & - \\
Corriere Sport & $(0.077)$ & 0 & $-0.174^{* * *}$ & 0 \\
& $9.518^{* * *}$ & - & $(0.021)$ & - \\
Gazzetta Sport & $(0.662)$ & 0 & $-0.103^{* * *}$ & 0 \\
& $5.616^{* * *}$ & - & $0.013)$ & - \\
Giornale & $(0.389)$ & $-0.106^{* * *}$ & 0 & - \\
& $5.777 * * *$ & $(0.013)$ & - & 0 \\
Repubblica & $(0.397)$ & $-0.021^{* * *}$ & 0 & - \\
& $1.174 * * *$ & $(0.003)$ & - & - \\
Il Sole & $(0.083)$ & 0 & 0 & 0 \\
& $2.230^{* * *}$ & - & - & - \\
Stampa & $(0.154)$ & $-0.040^{* * *}$ & 0 & - \\
& $2.199 * * *$ & $(0.005)$ & - & \\
\hline
\end{tabular}

We report the mean elasticities over the years 1992-2006. Bootstrapped standard errors based on 5k bootstrapped samples are reported in parentheses. Cells report the quantity change of the newspaper in the row following a change in the circulation of the newspaper in the column. Cross-circulation elasticities across different newspaper types are zero by construction. 


\section{Conclusion}

We study the role of multi-homing in the newspaper market. First, we build a micro-founded structural econometric model that encompasses the demand for differentiated products on both sides of the market and allows for multi-homing on each side of the market. We then estimate the model above alternatively taking into account and not taking into account information on multi-homing by readers. We show that incorporating multi-homing has important implications on both the readers side and the advertising side of the market.

Results for the readers' side of the market show that not accounting for multi-homing leads to a substantial bias in the estimation of own- and cross-price elasticities as well as own- and cross-network effect elasticities. In particular, mean own-price elasticities are substantially higher when multi-homing by readers is taken into account in the demand estimation. This is due to the fact that switching to a different bundle of newspapers is easier for a multi-homing reader than switching to a different newspaper is for a single-homing reader. Furthermore, while we find that newspapers of the same type are substitutes, newspapers of different types are found to be complements in the model accounting for multi-homing. However, a discrete choice model at the newspaper level assumes that all readers single-home and that all newspapers are substitutes.

Readers' multi-homing information also has important implications for the advertising side of the market. In particular, we find that own-price elasticities on the advertising side decrease with the share of exclusive readers while cross-price elasticities increase with the share of overlapping readers between newspapers. We also find that some newspapers are "must have" for advertisers, thanks to their large circulation and number of exclusive readers. These findings are largely consistent with the theoretical literature on multi-homing in two sided-markets, which stresses the role of readership composition (i.e. captive vs overlapping) for advertising demand.

Therefore, our paper contributes to the economic literature on two-sided markets, in which empirical work accounting for multi-homing is still quite scarce. Moreover, our contribution allows for a better understanding of how multi-homing by users in platform markets matters and how it influences price elasticities on both sides of the market. This is likely to bias the conclusions of such exercises as market definition or merger evaluation in which both own- and cross-price elasticities and own- and crossnetwork effect elasticities play a crucial role. Thus, it can be useful for competition and regulation authorities to improve their quantitative assessment in cases involving two-sided platforms.

While print newspapers are a classical example of an offline two-sided market, the empirical part of this paper should be seen as an application allowing for studying the role of multi-homing in (nontransaction) platform markets. The methodology can also be applied to other two-sided markets for which data on user multi-homing is available. Especially in light of the prevalence and rising importance of multi-sided platforms in digital markets and the relevance of multi-homing by users, the results and conclusions from this paper are also relevant in the context of competition policy cases involving online multi-sided platform markets. 


\section{References}

AfFeldt, P., L. Filistrucchi, And T. J. Klein (2013): "Upward Pricing Pressure in Two-Sided Markets," The Economic Journal, 123(572), F505-F523.

Alston, J. M., K. A. Foster, And R. D. Green (1994): "Estimating Elasticities with the Linear Approximate Almost Ideal Demand System: Some Monte Carlo Results," Review of Economics and Statistics, 76(2), 351-356.

Ambrus, A., E. Calvano, And M. Reisinger (2016): "Either or Both Competition: A 'TwoSided' Theory of Advertising with Overlapping Viewerships," American Economic Journal: Microeconomics, 8(3), 189-222.

ANDERSON, S. P., Ø. Foros, AND H. J. Kind (2018): "Competition for Advertisers and for Viewers in Media Markets," The Economic Journal, 128(608), 34-54.

Anderson, S. P., And J. J. Gabszewicz (2006): "The Media and Advertising: A Tale of Two-Sided Markets," in Handbook of the Economics of Art and Culture, ed. by V. A. Ginsburgh, and D. Throsby, vol. 1, pp. 567-614. Elsevier.

Anderson, S. P., ANd B. Jullien (2015): "The Advertising-Financed Business Model in TwoSided Media Markets," in Handbook of Media Economics, ed. by S. P. Anderson, J. Waldfogel, and D. Stromberg, vol. 1, pp. 41-90. NorthHolland.

Argentesi, E., And L. Filistrucchi (2007): "Estimating Market Power in a Two-Sided Market: The Case of Newspapers," Journal of Applied Econometrics, 22(7), 1247-1266.

Armstrong, M. (2006): "Competition in Two-Sided Markets," RAND Journal of Economics, 37(3), 668-691.

Athey, S., E. Calvano, And J. S. Gans (2018): “The Impact of Consumer Multi-Homing on Advertising Markets and Media Competition," Management Science, 64(4), 1574-1590.

Bakos, Y., AND H. Halaburda (2020): "Platform Competition with Multihoming on Both Sides: Subsidize or Not?," Management Science, 66(12), 5599-5607.

Berry, S., J. Levinsohn, And A. PAKes (1995): “Automobile Prices in Market Equilibrium,” Econometrica, 63(4), 841-890.

Berry, S. T. (1994): "Estimating Discrete-Choice Models of Product Differentiation," RAND Journal of Economics, 25(2), 242-262.

Caillaud, B., ANd B. Jullien (2001): “Competing Cybermediaries," European Economic Review, 45(4-6), 797-808.

(2003): "Chicken and Egg: Competition Among Intermediation Service Providers," RAND Journal of Economics, 34(2), 309-328.

Deaton, A., And J. Muellbauer (1980): “An Almost Ideal Demand System,” American Economic Review, 70(3), 312-326.

Evans, D. S. (2003): "The Antitrust Economics of Multi-Sided Platform Markets," Yale Journal on Regulation, 20(2), 325-382.

Evans, D. S., And R. SChMALEnSEe (2007): “The Industrial Organization of Markets with Two-Sided Platforms," Competition Policy International, 3(1), 151-179.

FAN, Y. (2013): "Ownership Consolidation and Product Characteristics: A Study of the U.S. Daily Newspaper Market," American Economic Review, 103(5), 1598-1628.

FILISTRUCCHI, L. (2005): “The Impact of Internet on the Market for Daily Newspapers in Italy," EUI Working Paper ECO No. 2005/12.

Filistrucchi, L., D. Geradin, E. Van Damme, and P. AfFeldt (2014): "Market Definition in Two-Sided Markets: Theory and Practice," Journal of Competition Law and Economics, 10(2), 293339. 
Filistrucchi, L., And T. J. Klein (2013): "Price Competition in Two-Sided Markets with Hetergoenous Consumers and Network Effetcs," NET Institute Working Paper No. 13-20.

FilistrucChI, L., T. J. Klein, And T. Michielsen (2012): "Assessing Unilateral Merger Effects in a Two-Sided Market: An Application to the Dutch Daily Newspaper Market," Journal of Competition Law and Economics, 8(2), 297-329.

GentzKow, M. (2007): "Valuing New Goods in a Model with Complementarity: Online Newspapers," American Economic Review, 97(3), 713-744.

Gentzkow, M., J. M. Shapiro, AND M. Sinkinson (2014): "Competition and Ideological Diversity: Historical Evidence from US Newspapers," American Economic Review, 104(10), 3073-3114.

Grzybowski, L., AND F. Verboven (2016): "Substitution between Fixed-Line and Mobile Access: the Role of Complementarities," Journal of Regulatory Economics, 49(2), 113-151.

Hausman, J., G. Leonard, and J. D. Zona (1994): "Competitive Analysis with Differentiated Products," Annales d'Economie et de Statistique, 34, 159-180.

Heien, D., AND G. Pompelli (1988): "The Demand for Beef Products: Cross-Section Estimation of Demographic and Economic Effects," Western Journal of Agricultural Economics, 13(1), 37-44.

IVAldi, M., AND C. Muller-Vibes (2018): “The Differentiated Effect of Advertising on Readership: Evidence from a Two-Sided Market Approach," Toulouse School of Economics Working Paper Number 18-900.

IVALDI, M., AND J. Zhang (2021): “Simulating Media Platform Mergers," International Journal of Industrial Organization, p. 102729.

Jeitschko, T. D., And M. J. Tremblay (2020): "Platform Competition with Endogenous Homing," International Economic Review, 61(3), 1281-1305.

Kaiser, U., AND J. Wright (2006): "Price Structure in Two-Sided Markets: Evidence from the Magazine Industry," International Journal of Industrial Organization, 24(1), 1-28.

LIU, Y.-H. (2018): “The Impact of Consumer Multi-Homing Behavior on Ad Prices: Evidence from an Online Marketplace," Mimeographed.

Neumann, N., C. E. Tucker, And T. Whitfield (2019): "Frontiers: How Effective is Third-Party Consumer Profiling? Evidence from Field Studies," Marketing Science, 38(6), 918-926.

Nevo, A. (2000): “A Practioner's Guide to Estimation of Random Coefficients Logit Models of Demand," Journal of Economics \& Management Strategy, 9(4), 513-548.

Parker, G. G., AND M. W. van Alstyne (2005): "Two-Sided Network Effects: A Theory of Information Product Design," Management Science, 51(10), 1494-1504.

Pinkse, J., And M. Slade (2004): "Mergers, Brand Competition and the Price of a Pint," European Economic Review, 48(3), 617-643.

Pinkse, J., M. Slade, and C. Brett (2002): "Spatial Price Competition: a Semiparametric Approach," Econometrica, 70(3), 1111-1155.

Rochet, J.-C., And J. Tirole (2002): "Cooperation among Competitors: Some Economics of Payment Card Associations," RAND Journal of Economics, 33(4), 549-570.

(2003): "Platform Competition in Two-Sided Markets," Journal of the European Economic Association, 1(4), 990-1029.

667.

RoJAS, C. (2008): "Price Competition in U.S. Brewing," The Journal of Industrial Economics, 56(1), $1-31$.

Rojas, C., And E. B. Peterson (2008): "Demand for Differentiated Products: Price and Advertising Evidence from the U.S. Beer Market," International Journal of Industrial Organization, 26(1), 288- 
307.

Rysman, M. (2004): "Competition between Networks: A Study of the Market for Yellow Pages," Review of Economic Studies, 71(2), 483-512.

(2007): “An Empirical Analysis of Payment Card Usage,” The Journal of Industrial Economics, 55(1), 1-36.

SHI, M. C. (2015): "Catching (Exclusive) Eyeballs: Multi-Homing and Platform Competition in the Magazine Industry," Mimeographed.

Slade, M. (2004): "Market Power and Joint Dominance in UK Brewing," The Journal of Industrial Economics, 52(1), 133-163.

SoKullu, S. (2016): "A Semi-Parametric Analysis of Two-Sided Markets: An Application to the Local Daily Newspapers in the USA," Journal of Applied Econometrics, 31, 843-864.

Song, M. (2021): "Estimating Platform Market Power in Two-Sided Markets with an Application to Magazine Advertising," American Economic Journal: Microeconomics, 13(2), 35-67.

VAN DER WurfF, R., P. BAKKer, AND R. G. PiCARD (2008): "Economic Growth and Advertising Expenditures in Different Media in Different Countries," Journal of Media Economics, 21(1), 28-52.

Wright, J. (2004): “One-Sided Logic in Two-Sided Markets," Review of Network Economics, 3(1), $44-64$. 


\section{A Appendix}

\section{A.1 Data Sources}

Table 12: Used Data and Corresponding Data Sources

\begin{tabular}{l|l}
\hline \hline Data & Source \\
\hline \hline Newspaper Data & \\
\hline Average prints & Accertamenti Diffusione Stampa \\
Cover prices & Newspaper publishers \\
Magazines, inserts, local pages, websites, editors & Newspaper publishers \\
Number of pages & Nielsen Media Research \\
Advertising quantities and revenues & Nielsen Media Research \\
Data on multi-homing readers & Audipress \\
Reader demographics (age groups, gender, socio- & Audipress \\
economic status) & \\
\hline Additional Data & \\
\hline Italian consumer price index & OECD \\
Italian population above 14 & ISTAT \\
Italian GDP & OECD \\
Paper price & Camera di Commercio di Milano \\
Hourly wage index printed media sector & ISTAT \\
Journalist hourly wage index & ISTAT \\
Electricity prices for industrial consumers & Eurostat \\
Italian internet penetration rate & ISTAT \\
\hline \hline
\end{tabular}




\section{A.2 Construction of Bundle Level Dataset}

In order to estimate readers' demand accounting for multi-homing by readers, we estimate a demand equation where consumers are allowed to read up to two newspapers (which is what we observe in the data). Thus, readers are allowed to choose between all possible pairs of newspapers, including singlehoming on a newspaper.

Hence, we construct a dataset in which the level of observation is no longer a newspaper at a particular point in time but a bundle of up to two newspapers for a given average weekday within a month.

We construct the monthly average circulation for each day of the week for a given bundle based on the survey data on multi-homing behavior of readers. First, for each newspaper we compute the share of single-homing (captive) readers, which also includes readers of other newspapers not included in our sample. Multiplying this share of single-homing readers with the circulation of the newspaper gives the circulation of the single-homing "bundle" at a particular point in time.

Constructing the circulation of a bundle of two newspapers is more complicated as double-homing reader percentages are not symmetric. For example, the percentage of readers of newspaper A who also read newspaper B will not be the same as the percentage of readers of newspaper B who also read newspaper A. However, multiplying these percentages with the respective newspaper circulation provides a lower and an upper bound for the circulation of the bundle of the two newspapers at a particular point in time.

We then must decide on the optimal point within the interval between lower and upper bound bundle circulation. Of course, setting bundle circulation to any value within this interval implies that, if we calculate newspaper circulation as the sum of the circulation of all bundles containing that particular newspaper, overall newspaper level circulation will not be equal to the actual circulation of that newspaper in the original data.

Therefore, we choose the optimal point in the interval between lower and upper bound bundle circulation so as to minimize the difference between actual and estimated newspaper circulation for the seven newspapers at each point in time. We do so by running constrained regressions for each half-year period (the interval at which we have information on reader multi-homing). The dependent variable in this regression is the circulation of the respective newspaper minus the single-homing circulation minus the lower bound circulations of all bundles including this newspaper. Hence, the dependent variable is the part of the total newspaper circulation that we still need to distribute across bundles. The independent variables are then the differences between upper and lower bound circulation for all possible bundles of two newspapers, where this difference is set to zero for all bundles that do not include the respective newspaper. We then run constrained OLS regressions, in which all the coefficients are constrained to lie between zero and one - thus, the estimated coefficients give us the optimal points in the respective intervals between lower and upper bound bundle circulation for all bundles of two newspapers. We repeat this constrained regression for every half year period in the dataset and construct the bundle circulation for all bundles of two newspapers based on the estimated optimal points in the interval between lower and upper bound bundle circulation.

As mentioned before, this procedure implies that if we collapse the bundle level dataset back to the newspaper level, circulation at the newspaper level will not be equal to the actual newspaper circulation 
of the original dataset. Table 13 shows the mean actual and mean estimated newspaper circulation as well as the mean percentage difference between the two. The percentage difference between actual and estimated newspaper circulation based on the constrained regression procedure is always lower than $8 \%$.

Table 13: Difference between Actual and Estimated Circulation by Newspaper

\begin{tabular}{lccc}
\hline Newspaper & Mean Actual Circulation & $\begin{array}{c}\text { Mean Estimated } \\
\text { Circulation }\end{array}$ & $\begin{array}{c}\text { Mean Percentage } \\
\text { Difference }\end{array}$ \\
\hline Corriere & 866,130 & 850,469 & 1.52 \\
Corriere Sport & 428,295 & 414,402 & 2.59 \\
Gazzetta Sport & 584,629 & 608,265 & -4.28 \\
Giornale & 315,328 & 292,570 & 7.24 \\
Repubblica & 799,423 & 808,024 & -1.48 \\
Il Sole & 462,816 & 443,114 & 4.22 \\
Stampa & 521,152 & 511,133 & 1.81 \\
\hline
\end{tabular}

The construction of the other variables in the bundle level dataset is straightforward: the bundle price is the sum of the two newspaper prices, advertising intensity is the sum of advertising slots in both newspapers divided by the total number of pages of the two newspapers, the paper cost is the sum of the two newspaper costs, and the number of local pages is the sum of the local pages of the two newspapers. For the other newspaper characteristics, which are dummy variables (for example the point in time when the newspaper introduced a website), we also calculate the sum of the two dummy variables. However, this variable will then only capture when, for example, the first website in the bundle was introduced. Therefore, we define additional variables for those product characteristics that capture the change from zero to one for the second newspaper included in the bundle. 


\section{A.3 Structure of Nests}

Figure 2: Structure of Nests - Single-Homing Readers' Demand

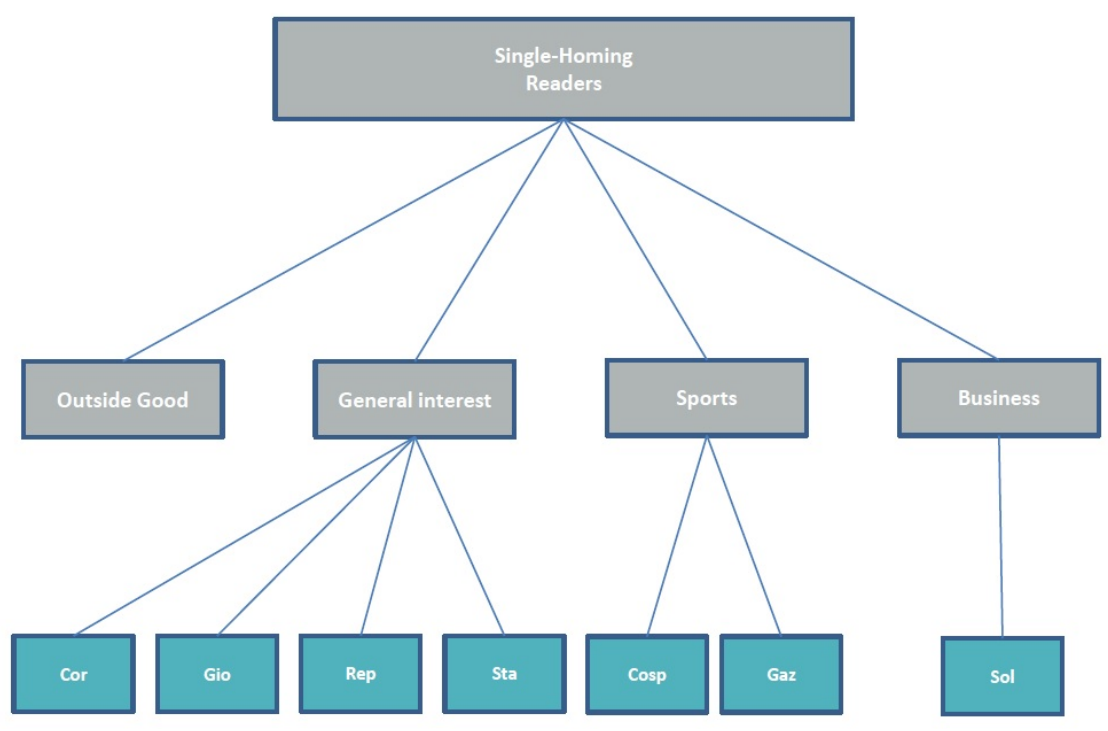

Figure 3: Structure of Nests - Double-Homing Readers' Demand

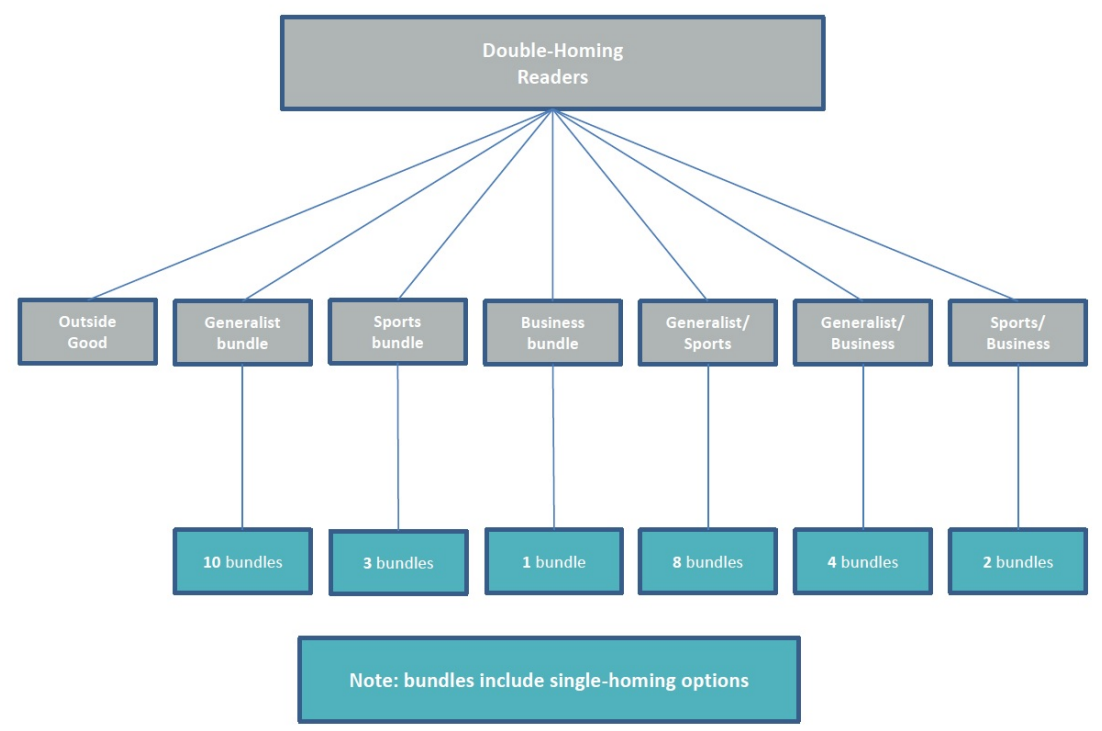




\section{A.4 Closeness Measures}

In the newspaper level advertisers' demand, we model the cross-price and cross-circulation coefficients $b_{j k t}$ and $c_{j k t}$ as linear functions of distance measures between newspapers $j$ and $k$. In particular, how close substitutes two newspapers are in the eyes of advertisers depends on how close these two newspapers are in characteristics space.

The closeness metrics are derived from differences among newspapers in the demographic characteristics of readers (age, gender, income), the amount of overlapping readers between the two newspapers, and the type of newspapers. Essentially, each closeness measure is a $7 \times 7$ matrix at each point in time (month $t$ and day of the week $d$ ) that specifies the closeness between all pairs of newspapers.

The closeness measures between newspapers for continuous product characteristics use an inverse measure of Euclidean distance. In particular, the closeness between newspapers $j$ and $k$ in terms of product characteristic $x$ is defined as $\frac{1}{1+2 \sqrt{\left(x_{j}-x_{k}\right)^{2}}}$. This ensures that the closeness measures between two newspapers vary between zero and one, so that a one implies that the two newspapers are at the same location in characteristic space. For example, if the characteristic under consideration is the percentage of female readers, the related closeness measure between two newspapers would be equal to one if they had exactly the same percentage of female readers. For closeness measures based on discrete product characteristics (for example the type of newspaper: generalist, sport, financial), the closeness between two newspapers is equal to one if they belong to the same group (i.e. are of the same type) and zero otherwise.

As an example, Table 14 shows the percentage of female readers as well as the newspaper type of each of the seven newspapers at a given point in time (here the second half of 2006 as the Audipress survey data on reader characteristics is bi-annual).

Table 14: Newspaper Characteristics Second Half 2006

\begin{tabular}{lcc}
\hline & Female readers $(\%)$ & Newspaper Type \\
\hline Corriere & 42.6 & Generalist \\
Corriere Sport & 10.0 & Sport \\
Gazzetta Sport & 10.4 & Sport \\
Giornale & 37.9 & Generalist \\
Repubblica & 43.8 & Generalist \\
Il Sole & 34.1 & Business \\
Stampa & 40.0 & Generalist \\
\hline
\end{tabular}

Table 15 shows the resulting closeness metric matrix based on the percentage of female readers for this particular point in time, while Table 16 shows the resulting closeness metric matrix based on the discrete newspaper type.

Going back to estimation equation (10), the closeness measures are then multiplied with the respective log price or circulation and summed up across newspapers. For example, let us assume that newspaper $j$ is Corriere della Sera and that cross-price elasticities between newspapers are a function of the closeness in female readers. For each of the other six newspapers, the closeness measure based on female readers between Corriere della Sera and the respective newspaper $k$ is multiplied with the log price of 
Table 15: Closeness Metric Based on Percentage of Female Readers - Second Half 2006

\begin{tabular}{lccccccc}
\hline & Corriere & $\begin{array}{c}\text { Corriere } \\
\text { Sport }\end{array}$ & $\begin{array}{c}\text { Gazzetta } \\
\text { Sport }\end{array}$ & Giornale & Repubblica & Il Sole & Stampa \\
\hline Corriere & - & 0.015 & 0.015 & 0.096 & 0.294 & 0.056 & 0.161 \\
Corriere Sport & 0.015 & - & 0.556 & 0.018 & 0.015 & 0.020 & 0.016 \\
Gazzetta Sport & 0.015 & 0.556 & - & 0.018 & 0.015 & 0.021 & 0.017 \\
Giornale & 0.096 & 0.018 & 0.018 & - & 0.078 & 0.116 & 0.192 \\
Repubblica & 0.294 & 0.015 & 0.015 & 0.078 & - & 0.049 & 0.116 \\
Il Sole & 0.056 & 0.020 & 0.021 & 0.116 & 0.049 & - & 0.078 \\
Stampa & 0.161 & 0.016 & 0.017 & 0.192 & 0.116 & 0.078 & - \\
\hline
\end{tabular}

Closeness metrics are rounded to three decimals.

Table 16: Closeness Metric Based on Newspaper Type

\begin{tabular}{lccccccc}
\hline & $\begin{array}{c}\text { Corriere } \\
\text { Corriere } \\
\text { Sport }\end{array}$ & $\begin{array}{c}\text { Gazzetta } \\
\text { Sport }\end{array}$ & Giornale & Repubblica & Il Sole & Stampa \\
\hline Corriere & - & 0 & 0 & 1 & 1 & 0 & 1 \\
Gazzetta Sport & 0 & - & 1 & 0 & 0 & 0 & 0 \\
Giornale & 0 & 1 & - & 0 & 0 & 0 & 0 \\
Repubblica & 1 & 0 & 0 & - & 1 & 0 & 1 \\
Il Sole & 0 & 0 & 0 & 1 & - & 0 & 1 \\
Stampa & 1 & 0 & 0 & 0 & 0 & - & 0 \\
\hline
\end{tabular}

newspaper $k$. These six interaction terms are summed up into one term included in the regression. Thus, for each closeness/cross-price interaction one $\lambda$ is estimated and for each closeness/cross-circulation interaction one $\tau$ is estimated. The cross-price and cross-circulation coefficients $b_{j k t}$ and $c_{j k t}$ are then recovered by replacing the estimated coefficients $\lambda_{l}$ and $\tau_{m}$ and the closeness measures $\delta_{j k t}$ and $\mu_{j k t}$ into equations (8) and (9), respectively. 


\section{A.5 Elasticities Advertisers' Demand}

\section{A.5.1 Conditional Price Elasticities}

Differentiating the advertising sales share $w_{j t}$ of newspaper $j$ at time $t$ with respect to own- and crossprices $\left(p_{j t}\right.$ and $\left.p_{k t}\right)$, holding $x_{t}$ constant, gives:

$$
\frac{\partial w_{j t}}{\partial p_{k t}}= \begin{cases}\frac{\partial\left(p_{j t} q_{j t} / x_{t}\right)}{\partial p_{j t}}=\frac{q_{j t}}{x_{t}}+\frac{p_{j t}}{x_{t}} \frac{\partial q_{j t}}{\partial p_{j t}}=\frac{q_{j t}}{x_{t}}+\frac{p_{j t}}{x_{t}} \frac{\partial q_{j t}}{\partial p_{j t}} \frac{q_{j t}}{q_{j t}}=\frac{q_{j t}}{x_{t}}+\frac{q_{j t}}{x_{t}} \tilde{\eta}_{j j} & \text { if } k=j \\ \frac{\partial\left(p_{j t} q_{j t} / x_{t}\right)}{\partial p_{k t}}=\frac{p_{j t}}{x_{t}} \frac{\partial q_{j t}}{\partial p_{k t}}=\frac{p_{j t}}{x_{t}} \frac{\partial q_{j t}}{\partial p_{k t}} \frac{p_{k t}}{q_{j t}} \frac{q_{j t}}{p_{k t}}=\frac{w_{j t}}{p_{k t}} \tilde{\eta}_{j k} & \text { if } k \neq j\end{cases}
$$

Solving for $\tilde{\eta}_{j j}$ and $\tilde{\eta}_{j k}$ gives:

$$
\tilde{\eta}_{j k}= \begin{cases}\frac{x_{t}}{q_{j t}} \frac{\partial w_{j t}}{\partial p_{j t}}-1 & \text { if } k=j \\ \frac{\partial w_{j t}}{\partial p_{k t}} \frac{p_{k t}}{w_{j t}} & \text { if } k \neq j\end{cases}
$$

Now, given the functional form of the estimation equation for $w_{j t}$ in equation (10), the own- and cross-price derivatives, $\frac{\partial w_{j t}}{\partial p_{j t}}$ and $\frac{\partial w_{j t}}{\partial p_{k t}}$, are the following:

$$
\frac{\partial w_{j t}}{\partial p_{k t}}= \begin{cases}\frac{\partial w_{j t}}{\partial \ln \left(p_{j t}\right)} \frac{\partial \ln \left(p_{j t}\right)}{\partial p_{j t}}=\frac{1}{p_{j t}} \frac{\partial w_{j t}}{\partial \ln \left(p_{j t}\right)}=\frac{1}{p_{j t}}\left[b_{j j t}-d_{j} w_{j t}\right] & \text { if } k=j \\ \frac{\partial w_{j t}}{\partial \ln \left(p_{k t}\right)} \frac{\partial \ln \left(p_{k t}\right)}{\partial p_{k t}}=\frac{1}{p_{k t}} \frac{\partial w_{j t}}{\partial \ln \left(p_{k t}\right)}=\frac{1}{p_{k t}}\left[b_{j k t}-d_{j} w_{k t}\right] & \text { if } k \neq j\end{cases}
$$

Lastly, the conditional own- and cross-price elasticities are obtained by replacing (16) into (15):

$$
\tilde{\eta}_{j k}= \begin{cases}-1+\frac{b_{j j t}}{w_{j t}}-d_{j} & \text { if } k=j \\ \frac{b_{j k t}}{w_{j t}}-d_{j} \frac{w_{k t}}{w_{j t}} & \text { if } k \neq j\end{cases}
$$

Note that the $b_{j j t}$ potentially is a function of own product characteristic while $b_{j k t}$ is a function of the closeness measures.

\section{A.5.2 Unconditional Price Elasticities}

Compared to the price elasticities of advertising demand $\tilde{\eta}_{j k}$ conditional on total advertising expenditures $x_{t}$, the unconditional advertising price elasticities $\eta_{j k}$ also need to take into account how advertising price increases by one newspaper change the overall price index for advertising in newspapers, how this in turn then changes the overall demand for advertising in print newspapers at the top level (relative to other media outlets), and how this change in total advertising expenditures $x_{t}$ then affects the advertising quantity demanded on newspaper $j$. See Heien and Pompelli (1988) for the general formula of the total own-price elasticity in the AIDS model.

Given the functional form of the estimation equations in equations (5) and (10) and the choice of the price index $P_{t}$, the unconditional price-elasticities for advertising demand $\eta_{j k}$ are given by:

$$
\eta_{j k}= \begin{cases}\tilde{\eta}_{j j}+\left(1+\frac{d_{j}}{w_{j t}}\right)\left(\beta_{2}+1\right) w_{j t} & \text { if } k=j \\ \tilde{\eta}_{j k}+\left(1+\frac{d_{j}}{w_{j t}}\right)\left(\beta_{2}+1\right) w_{k t} & \text { if } k \neq j\end{cases}
$$

The additional term in comparison to the conditional price elasticities of advertising demand $\tilde{\eta}_{j k}$ is 
the percentage change in advertising quantity $q_{j t}$ demanded on newspaper $j$ following an advertising price increase of newspaper $k$ that goes via its effect on total advertising expenditure $x_{t}$ :

- $w_{k t}$ is the elasticity of the price index $P_{t}$ with respect to a change in the advertising price of newspaper $k, p_{k t}$.

- $\left(\beta_{2}+1\right)$ is the elasticity of total advertising expenditure $x_{t}$ with respect to a change in the price index $P_{t}$ (Heien and Pompelli, 1988, p.40), where $\beta_{2}$ is the overall price elasticity of advertising demand in the seven newspapers relative to other media outlets estimated at the top level (see top level estimation equation (5)).

- $\left(1+\frac{d_{j}}{w_{j t}}\right)$ is the expenditure elasticity, i.e. by how much a change in total advertising expenditure $x_{t}$ changes the advertising quantity $q_{j t}$ demanded on newspaper $j$ (Alston, Foster, and Green, 1994, p.352). If a change in total advertising expenditure $x_{t}$ leaves the advertising sales share of newspaper $j, w_{j t}$, unchanged (i.e. the estimated $d_{j}$ in equation (10) is zero), the expenditure elasticity is 1 . If, instead, $w_{j t}$ changes with a change in $x_{t}$, the expenditure elasticity of newspaper $j$ depends on the estimated $d_{j}$.

\section{A.5.3 Circulation Elasticities}

Circulation elasticities, which do not depend on total advertising expenditures $x_{t}$, are derived in a similar way as the conditional price elasticities. Differentiating the advertising sales share $w_{j t}$ of newspaper $j$ at time $t$ with respect to own- and cross-circulation $\left(\operatorname{circ}_{j t}\right.$ and $\left.\operatorname{circ}_{k t}\right)$ gives:

$$
\frac{\partial w_{j t}}{\partial \operatorname{circ}_{k t}}= \begin{cases}\frac{\partial\left(p_{j t} q_{j t} / x_{t}\right)}{\partial \operatorname{cir}_{j t}}=\frac{p_{j t}}{x_{t}} \frac{\partial q_{j t}}{\partial \operatorname{circ}_{j t}}=\frac{p_{j t}}{x_{t}} \frac{\partial q_{j t}}{\partial \operatorname{cir}_{j t}} \frac{\operatorname{circ}_{j t}}{q_{j t}} \frac{q_{j t}}{\operatorname{circ}_{j t}}=\frac{w_{j t}}{\operatorname{circ}_{j t}} \rho_{j j} & \text { if } k=j \\ \frac{\partial\left(p_{j t} q_{j t} / x_{t}\right)}{\partial \operatorname{cir}_{k t}}=\frac{p_{j t}}{x_{t}} \frac{\partial q_{j t}}{\partial \operatorname{cir} c_{k t}}=\frac{p_{j t}}{x_{t}} \frac{\partial q_{j t}}{\partial \operatorname{circ}_{k t}} \frac{\operatorname{circ}_{k t}}{q_{j t}} \frac{q_{j t}}{\operatorname{circ}_{k t}}=\frac{w_{j t}}{\operatorname{circ}_{k t}} \rho_{j k} & \text { if } k \neq j\end{cases}
$$

Solving for $\rho_{j j}$ and $\rho_{j k}$ gives:

$$
\rho_{j k}= \begin{cases}\frac{\partial w_{j t}}{\partial \operatorname{cir}_{j t}} \frac{\operatorname{circ}_{j t}}{w_{j t}} & \text { if } k=j \\ \frac{\partial w_{j t}}{\partial \operatorname{cir} c_{k t}} \frac{\operatorname{circ}_{k t}}{w_{j t}} & \text { if } k \neq j\end{cases}
$$

Given the functional form of the estimation equation for $w_{j t}$ in equation (10), the own- and crosscirculation derivatives, $\frac{\partial w_{j t}}{\partial \operatorname{circ}_{j t}}$ and $\frac{\partial w_{j t}}{\partial \text { circ }_{k t}}$, are the following:

$$
\frac{\partial w_{j t}}{\partial \operatorname{circ}_{k t}}= \begin{cases}\frac{\partial w_{j t}}{\partial \ln \left(\operatorname{cir}_{j t}\right)} \frac{\partial \ln \left(\operatorname{circ}_{j t}\right)}{\left.\partial \operatorname{circ}_{j t}\right)}=\frac{1}{\operatorname{circ} c_{j t}} \frac{\partial w_{j t}}{\partial \ln \left(\operatorname{cir}_{j t}\right)}=\frac{c_{j j t}}{\operatorname{circ}_{j t}} & \text { if } k=j \\ \frac{\partial w_{j t}}{\partial \ln \left(\operatorname{cir}_{k t}\right)} \frac{\partial \ln \left(\operatorname{circ}_{k t}\right)}{\partial \operatorname{circ}_{k t}}=\frac{1}{\operatorname{circ}_{k t}} \frac{\partial w_{j t}}{\partial \ln \left(\operatorname{cir}_{k t}\right)}=\frac{c_{j k t}}{\operatorname{circ}_{k t}} & \text { if } k \neq j\end{cases}
$$

Lastly the own- and cross-circulation elasticities are obtained by replacing (21) into (20):

$$
\rho_{j k}= \begin{cases}\frac{c_{j j t}}{w_{j t}} & \text { if } k=j \\ \frac{c_{j k t}}{w_{j t}} & \text { if } k \neq j\end{cases}
$$

with $c_{j j t}$ potentially being a function of own product characteristics and $c_{j k t}$ being a function of the closeness measures. 


\section{A.6 Determinants of Advertisers' Demand Elasticities}

Table 17: Mean Characteristics by Newspaper (1992-2006)

\begin{tabular}{lccc}
\hline & $\begin{array}{c}\text { Advertising expenditure } \\
\text { share }\end{array}$ & $\begin{array}{c}\text { Percentage of female } \\
\text { readers }\end{array}$ & $\begin{array}{c}\text { Percentage of } \\
\text { single-homing readers }\end{array}$ \\
\hline Corriere & 28.06 & 40.97 & 45.82 \\
Corriere Sport & 3.94 & 13.08 & 41.45 \\
Gazzetta Sport & 6.21 & 12.67 & 50.08 \\
Giornale & 5.6 & 38.44 & 29.02 \\
Repubblica & 26.22 & 41.24 & 51.42 \\
Il Sole & 16.25 & 33.55 & 25.03 \\
Stampa & 14.24 & 41.7 & 61.63 \\
\hline
\end{tabular}




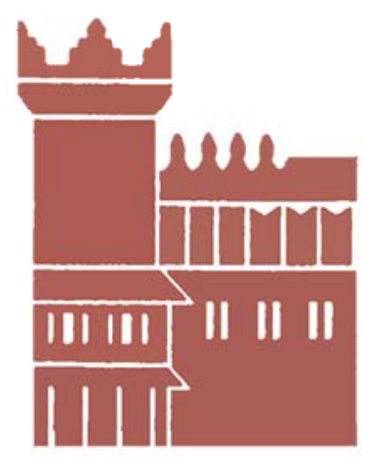

Alma Mater Studiorum - Università di Bologna DEPARTMENT OF ECONOMICS

Strada Maggiore 45

40125 Bologna - Italy

Tel. +39051 2092604

Fax +390512092664

http://www.dse.unibo.it 